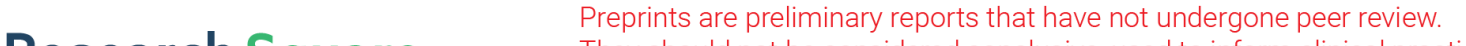 They should not be considered conclusive, used to inform clinical practice, or referenced by the media as validated information. \\ Bowl Surface Laser Forming Process of Stainless Steel Composite Plate
}

\section{Xiaogang Wang}

College of Electromechanical Engineering, China University of Petroleum (East China), Qingdao, 266580, China

\section{Yongjun Shi ( $\nabla$ Shiyj_upc@126.com )}

China University of Petroleum Huadong

\section{Yankuo Guo}

College of Electromechanical Engineering, China University of Petroleum (East China), Qingdao, 266580, China

\section{Qin Wang}

College of Electromechanical Engineering, China University of Petroleum (East China), Qingdao, 266580, China

\section{Research Article}

Keywords: Stainless steel composite plate, Three-dimensional bowl surface, Scanning strategy, Process conditions, Forming accuracy

Posted Date: June 14th, 2021

DOl: https://doi.org/10.21203/rs.3.rs-580752/v1

License: (9) This work is licensed under a Creative Commons Attribution 4.0 International License. Read Full License

Version of Record: A version of this preprint was published at Journal of Physics: Conference Series on June 1st, 2021. See the published version at https://doi.org/10.1088/1742-6596/1948/1/012156. 


\title{
Bowl Surface Laser Forming Process of Stainless Steel \\ Composite Plate
}

\author{
Xiaogang Wang, Yongjun Shi*, Yankuo Guo, Qin Wang \\ College of Electromechanical Engineering, China University of Petroleum (East China), Qingdao, \\ 266580, China
}

\begin{abstract}
In this paper, the three-dimensional bowl surface was obtained by reasonably planning the radial heating path by taking the laser as the heat source and the stainless steel composite plate (06Cr19Ni10/1Cr17Mn6Ni5N/06Cr19Ni10) as the research object, and the forming process of the three-dimensional bowl surface was studied. It was found that the target surface bending forming obtained by inside-outside symmetric scanning strategy (Strategy d) had the highest accuracy. The plate deformation increased with the increase of laser power $(P)$, increased then decreased with the increase of heating line length $(L)$, and decreased with the increase of scanning speed $(V)$. Moreover, the deformation was approximately linear with the number of repeated heating $(N)$, with the optimal process conditions of $P=500 \mathrm{~W}, V=10 \mathrm{~mm} / \mathrm{s}, L$ $=20 \mathrm{~mm}, N=7$. A three-dimensional thermodynamic coupling model of a three-layer composite plate was established and verified experimentally.
\end{abstract}

Keywords: Stainless steel composite plate, Three-dimensional bowl surface, Scanning strategy, Process conditions, Forming accuracy

\section{Introduction}

With the help of laser heat source, laser forming forms a temperature gradient in the material thickness direction, which in turn induces heterogeneous thermal stress. Moreover, with the help of plastic strain difference in the material thickness direction, it realizes the bending deformation of the material ${ }^{[1-5]}$.

According to the shape division of the target surface, laser shaping can be divided into two-dimensional single curvature (V-shaped structure) shaping and three-dimensional multiple curvature shaping.

Initially, research on laser forming mainly focused on two-dimensional single curvature forming of metallic materials. Kotobi et al. ${ }^{[6]}$ studied the deformation behavior of St-Ti bilayer composites under different laser parameters. It was found that the bending angle and residual

\footnotetext{
* Corresponding author.

E-mail address:shiyj_upc@126.com.
} 
stress increased with the increase of laser power $P$ and heating times $N$, and decreased with the increase of scanning speed $V$, spot diameter $D$, and plate thickness $T$, moreover, the bending angle was predicted by neural network. Kalvettukaran et al. ${ }^{[7]}$ studied the effect of cooling mode on bending angle in laser forming process by numerical simulation. It was found that the temperature difference between upper and lower surfaces of plate could be significantly increased by water cooling mode, and the bending angle could be increased by $2 \%$. The numerical model was verified by experimental method. Rattan et al. ${ }^{[8]}$ studied the effect of lime coated on the bending angle of common carbon steel. It is found that when the surface temperature on the material was the same, there was increased bending angle of lime coated material, and the angle decreased with the increase of coating thickness. Biplab et al. ${ }^{[9]}$ obtained the optimum forming process by Taguchi method and ANOVA. Under this process, the maximum bending angle of the plate was $5.1^{\circ}$. At the same time, the relationship between bending angle and laser power, scanning speed, spot diameter, and scanning times was obtained by regression analysis. After fully studying the three mechanisms of laser shaping (TGM, BM, UM), Shi et al. ${ }^{[10]}$ proposed a coupling mechanism (CM) on this basis, which could simultaneously underwent bending deformation with in-plane deformation.

In recent years, two-dimensional single curvature deformation has been unable to meet the needs of industrial production, and three-dimensional multiple curvature complex forming has become a research hotspot. Tavakoli et al. ${ }^{[1]}$ planned a number of hexagonal heating paths with different side lengths on AISI 304 circular plates, and the three-dimensional bowl surface was obtained, furthermore, the effects of the starting point and direction of the heating line on the edge height and forming accuracy of the target surface were studied. Gisario et al. ${ }^{[12]}$ compared the effects of radial scanning strategy, circumferential scanning strategy, radial scanning strategy combined with circumferential scanning strategy on the forming law of arch surface. It was found that radial scanning strategy was the simplest and most accurate method for arch surface. Through the "spider" scanning strategy, Shahabad et al. ${ }^{[13]}$ obtained the arch surface using Al6061 plate, and it was found that the arch height was directly proportional to the laser power and inversely proportional to the scanning speed and spot diameter.

According to the type of materials, laser forming materials can be divided into single-layer metal materials and multi-layer metal/non-metal composites. Among them, multi-layer composites 
combine two or more metal/non-metal materials by rolling, explosion and other means, so as to achieve the purpose of exerting the advantages of multiple materials at the same time.

Wang et al. ${ }^{[14]}$ studied the forming law of three-layer stainless steel-low carbon steel material under arc scanning strategy. It was found that the plate underwent double curvature deformation under arc scanning line, the free end curvature increased with the increase of scanning line curvature, the bending angle increased with the increase of laser power when the laser power was less than $700 \mathrm{~W}$, and the bending angle was directly proportional to $H_{e}$ (the distance between the top of arc heating line and the end of plate). Zhang et al. ${ }^{[15]}$ studied the deformation behavior of three-layer $\mathrm{Ni} / \mathrm{Cu} / \mathrm{Ni}$ metal sheets under the action of high-speed laser. It was found that the surface roughness of the formed part became larger with the increase of laser power, the microhardness of the surface material increased, and there was no delamination failure phenomenon during the forming process. Taking metal foam plate as the research object, Bucher et al. ${ }^{[16]}$ obtained the bowl surface and saddle surface by using the circumferential scanning line and radial scanning line, respectively. It was found that the influence of scanning line length on the formation of foam plate was more important than that of common metal materials. Chen et al. ${ }^{[17]}$ studied the deformation behavior of two types of Al-Si metal foam plates, large- and small-pore under the action of laser. It was found that the bending angle of the two types of foam plates increased with the increase of laser power, which showed a decreased trend with the increase of scanning speed. Under the same operating conditions, the bending angle of the large-pore metal foam plate was larger.

For the laser forming of composite plate, the thermophysical parameters and mechanical parameters of each layer of material were different, which brought great challenges to the laser forming. In this paper, a three-dimensional nonlinear thermodynamic coupling model was established using a three-layer stainless steel composite plate (06Cr19Ni10/1Cr17Mn6Ni5N/06Cr19Ni10) as the research object, so as to study its bowl surface forming law in the radial scanning mode. Moreover, this model was verified by the experimental method to provide a technical reference for the three-dimensional complex bending forming of composite plate.

\section{Simulation}

2.1 Numerical thermodynamic coupling model 
The nonlinear thermodynamic coupling model of three-layer stainless steel composite plate was established by ABAQUS finite element analysis software. By thermodynamic analysis module, simulated analysis was conducted for the temperature field, deformation field and stress-strain field of composite plate in the process of laser forming. Figure 1 shows the schematic diagram of the plate model.

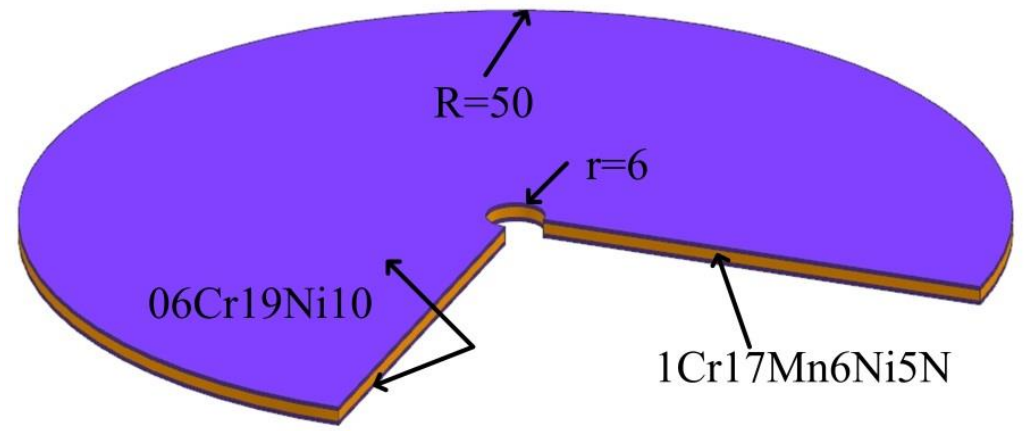

Figure 1 Schematic of Simulation Model

\subsection{Mesh}

The hexahedral 8-node 'C3D8T' was selected as the analysis unit and used as the three-dimensional structural entity unit, which could obtain the displacement and temperature during the three-dimensional nonlinear coupling process. The upper and lower overlays (06Cr19Ni10) were meshed with 2 layers along the thickness direction, and the middle base layer $(1 \mathrm{Cr} 17 \mathrm{Mn} 6 \mathrm{Ni5N})$ was meshed with 6 layers along the thickness direction, with a total number of nodes of 24,000 .

\subsection{Assumption}

During the forming process, the room temperature was maintained at $25^{\circ} \mathrm{C}$ all the time; the self-weight of the composite plate itself was ignored; due to the large laser energy, the heat generated due to plastic deformation during the forming process was not considered; the composite plate remained isotropic; before the laser forming, the composite plate did not undergo bending deformation, and the residual stress was 0 ; the composite plate obeyed the Von-Mises yield criterion. Considering the variation of the material's thermophysical parameters with temperature, Fig. 2 shows thermophysical parameters of the laminated stainless steel plate. 

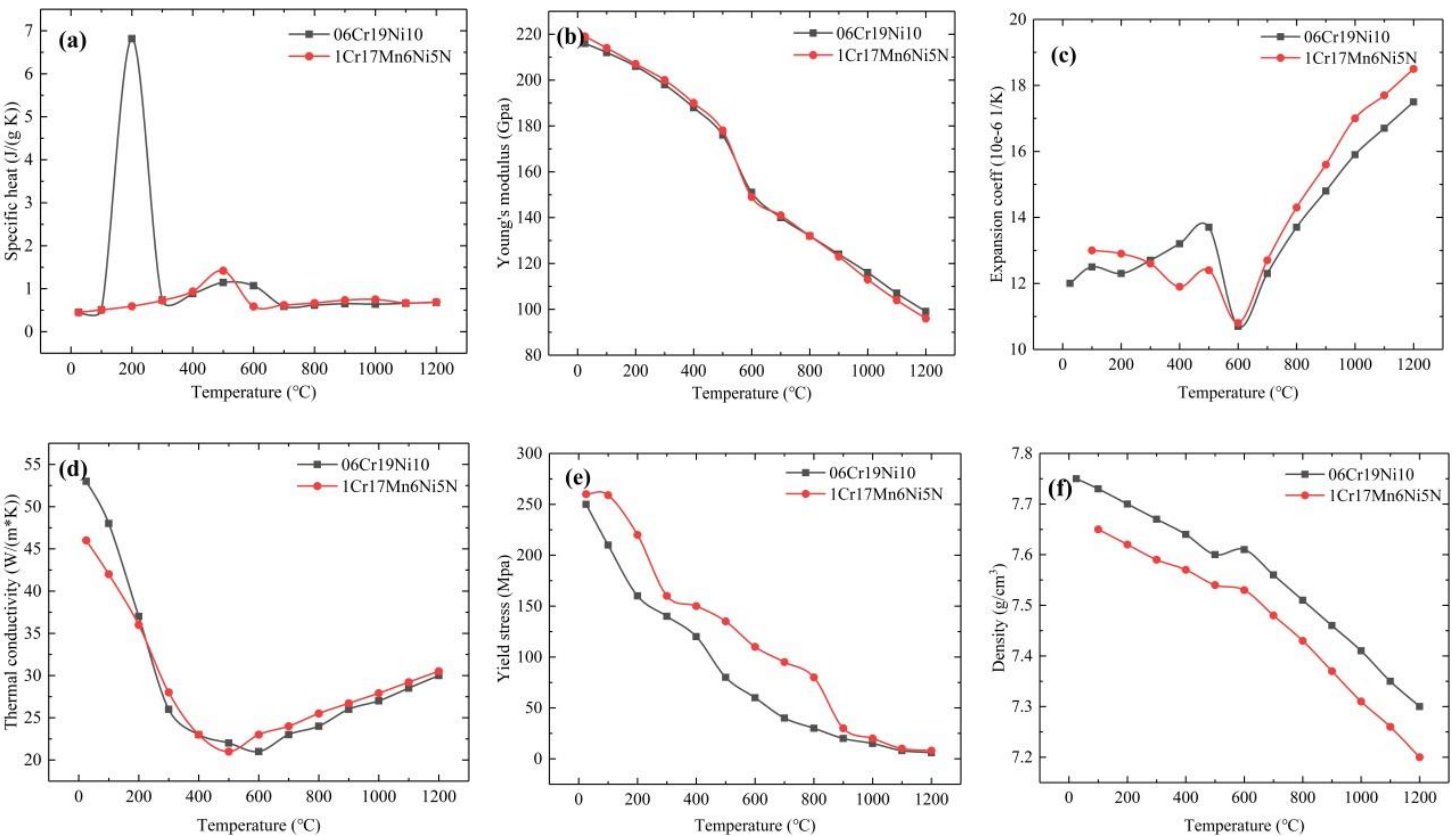

Fig. 2 Thermophysical parameters of laminated stainless steel plate.

\section{Experimental}

\subsection{Plates}

In the experiment, three-layer stainless steel plate (06Cr19Ni10/1Cr17Mn6Ni5N/06Cr19Ni10) made by rolling process had a total thickness of $1.2 \mathrm{~mm}$ : the upper and lower surfaces adopted 06Cr19Ni10 stainless steel (thickness: $0.08 \mathrm{~mm}$ ) and the middle surface adopted $1 \mathrm{Cr} 17 \mathrm{Mn} 6 \mathrm{Ni} 5 \mathrm{~N}$ stainless steel (thickness: $1.04 \mathrm{~mm}$ ). The plate was cut by laser. Table 1 shows the elemental composition of the stainless steel composite.

Table.1 Composition of stainless steel laminated sheet (\%)

\begin{tabular}{cccccccccc}
\hline Elements & $\mathrm{C}$ & $\mathrm{Si}$ & $\mathrm{Mn}$ & $\mathrm{S}$ & $\mathrm{P}$ & $\mathrm{Cr}$ & $\mathrm{Ni}$ & $\mathrm{Ti}$ & $\mathrm{N}$ \\
\hline 06Cr19Ni10 & 0.07 & 1 & 2 & 0.03 & 0.035 & 19 & 10 & 0.4 & \\
1 Cr17Mn6Ni5N & 0.15 & 1 & 6.5 & & & 17 & 4.5 & & 0.25 \\
\hline
\end{tabular}

\subsection{Experimental methods}

Figure 3 shows the laser forming experimental device. MFSC-2000 single-module continuous optical fiber laser was used in the experiment, with a maximum output power of $2 \mathrm{KW}$ and a wavelength range of $1060 \mathrm{~nm} \sim 1100 \mathrm{~nm}$; Flir-A615 infrared thermal imager was used to collect the surface temperature of metal plate during the experiment. The temperature measurement range of the infrared thermal imaging camera was $-50 \sim 2000^{\circ} \mathrm{C}$, the time response was $8 \mathrm{~ms}$, the spatial resolution was $0.68 \mathrm{mrad}$, and the measurement error range of infrared thermal imaging camera was within $\pm 2 \%$; the deformation of the formed sample was measured by 
Global (Italy Made), with the measurement accuracy of 0.002 .

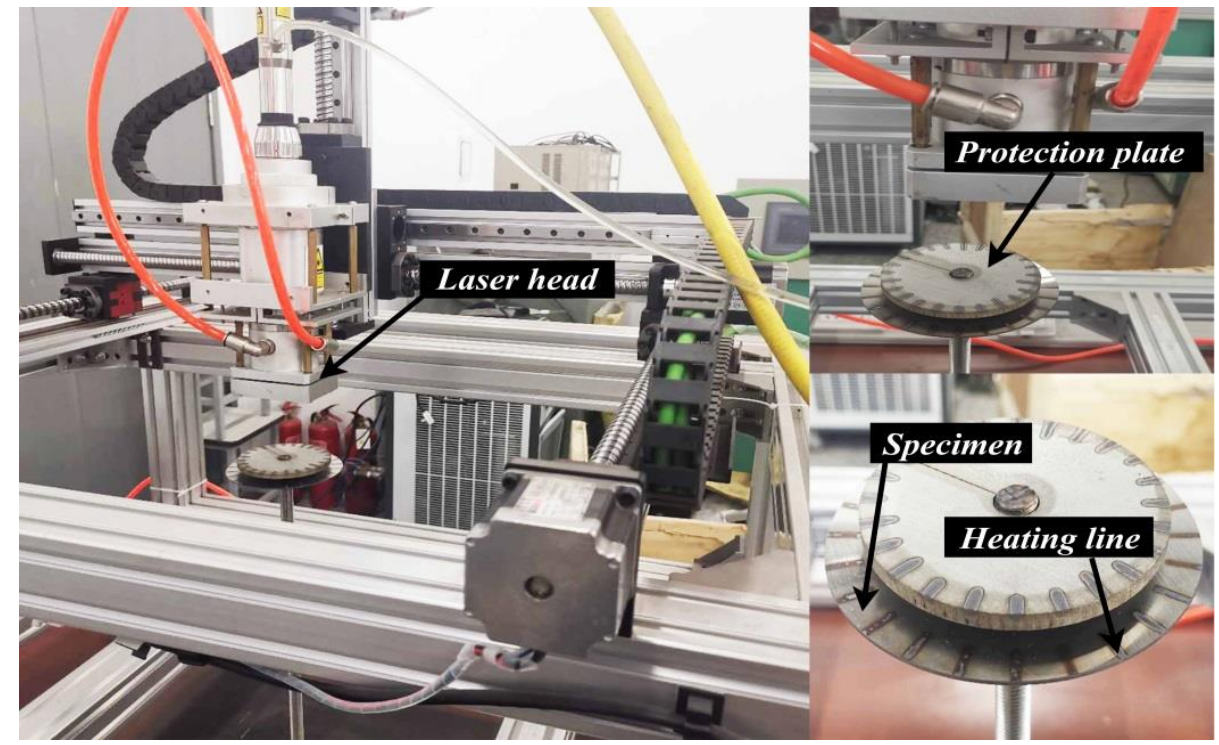

Figure 3 Experimental set-up of laser forming

Laser cutting was adopted as the plate cutting mode. Before the start of the experiment, the surface of the stainless steel composite was cleaned with a mixture of ethanol and acetone to eliminate the effect of oil scale on the experimental results. To duplicate the truly production conditions, graphite was not applied on the surface of the plate in the experiment. After the completion of processing, it was naturally cooled to room temperature. During the machining process, the stud passed through the inner hole of the plate, and the plate was fixed with a nut up and down, with 0 degrees of freedom in the three directions of $\mathrm{X}, \mathrm{Y}$, and $\mathrm{Z}$. The plate did not rotate around the $\mathrm{Z}$-axis, and to ensure that the laser was in a stable state after reaching the plate surface, a protective plate was set above the plate. The average displacement and relative displacement of 8 characteristic points in the vertical direction at the edge position of the plate shown in Figure 4 were used as the criteria for evaluating the deformation degree and forming accuracy of the formed part. 


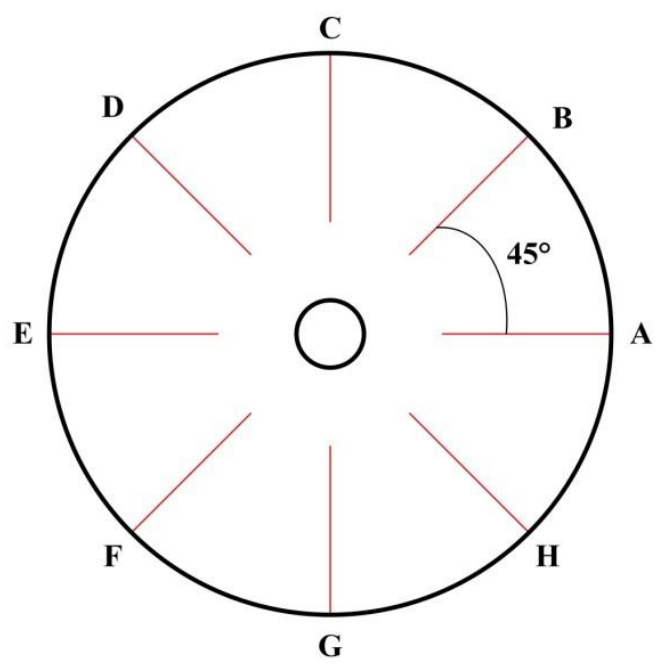

Figure 4 Diagram of feature points of plate

Relative height change of each position at the plate edge $\Delta H=H_{i}-H_{0}$, where, $H_{i}$ is vertical displacement at each position of edge , $i=A \sim H, \quad H_{0}$ is the vertical displacement height of the starting end. Relative change rate of vertical displacement at each position $\eta=\left(H_{\max }-H_{\min }\right) / H_{\text {ave }}$ where $H_{\max }$ represents the maximum displacement height, $H_{\min }$ indicates the smallest displacement height, $H_{\text {ave }}$ represents average displacement height .

\subsection{Laser scanning strategy}

Figure 5 shows the schematic diagram of the laser scanning strategy. The laser source moves along the radius direction, there are a total of 24 heating lines. The laser spot movement direction shown in Figure 5 (a) is outside-inside, in Figure 5 (b), inside-outside scanning strategy. The scanning sequence under both scanning strategies is along the counterclockwise direction. Figure 5 (c) (d) shows a symmetric radial scanning strategy with the front and back heating lines separated by $180^{\circ}$, and the numbers in the figure represent the scanning order of the heating lines, where 1 represents the first heating line and 24 represents the last heating line. The heating line shown in Figure 5 (c) is oriented outside-inside, and in Figure 5 (d), oriented inside-outside. The Strategy $(\mathrm{a} \sim \mathrm{d})$ mentioned below represents the four scanning strategies of Figure $5(\mathrm{a} \sim \mathrm{d})$, respectively. 
(a)

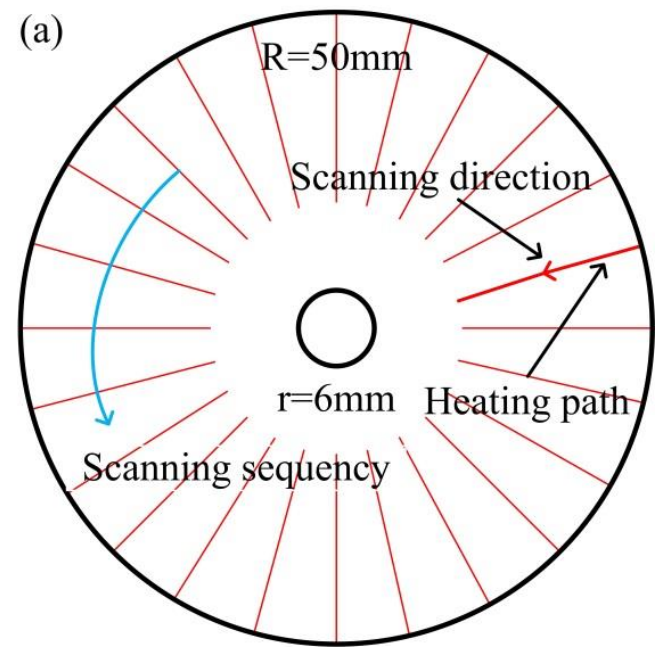

(c)

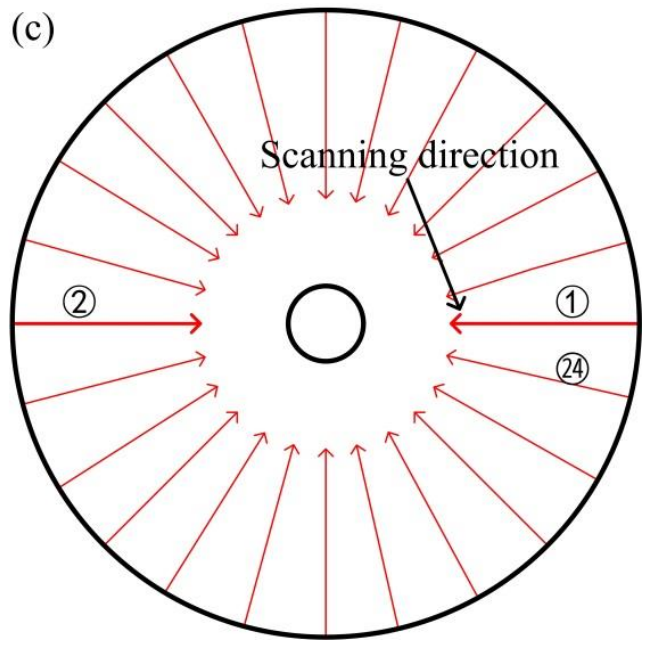

(b)

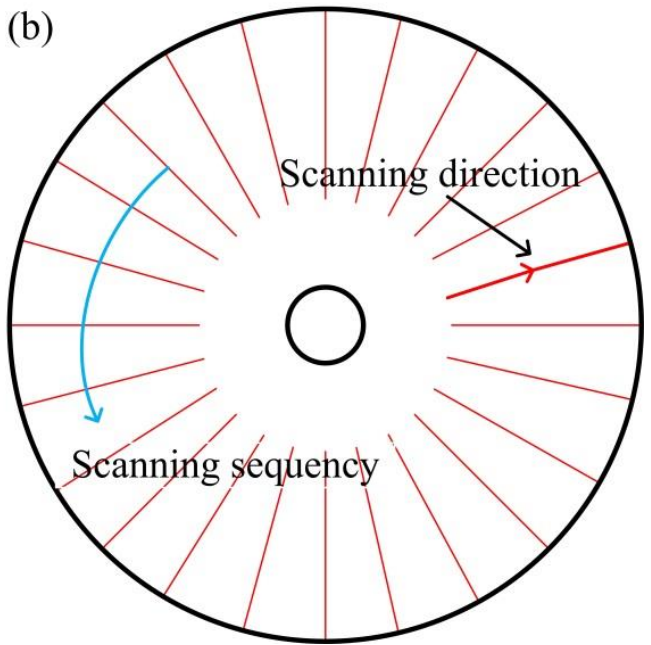

(d)

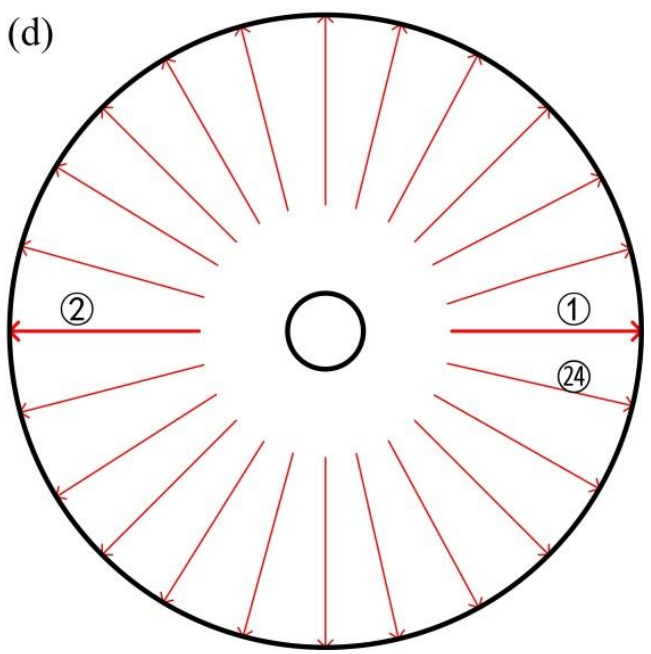

Figure 5 Diagram of laser scanning strategy. (a) Scanning strategy a;(b) Scanning strategy b;(c) Scanning strategy;(d) Scanning strategy

\subsection{Numerical simulation test verification}

To verify the reliability of establishing the numerical model, the numerical simulation under the same operating condition was compared with the experimental data, and the numerical simulation and experimental results are shown in Figure 6. 

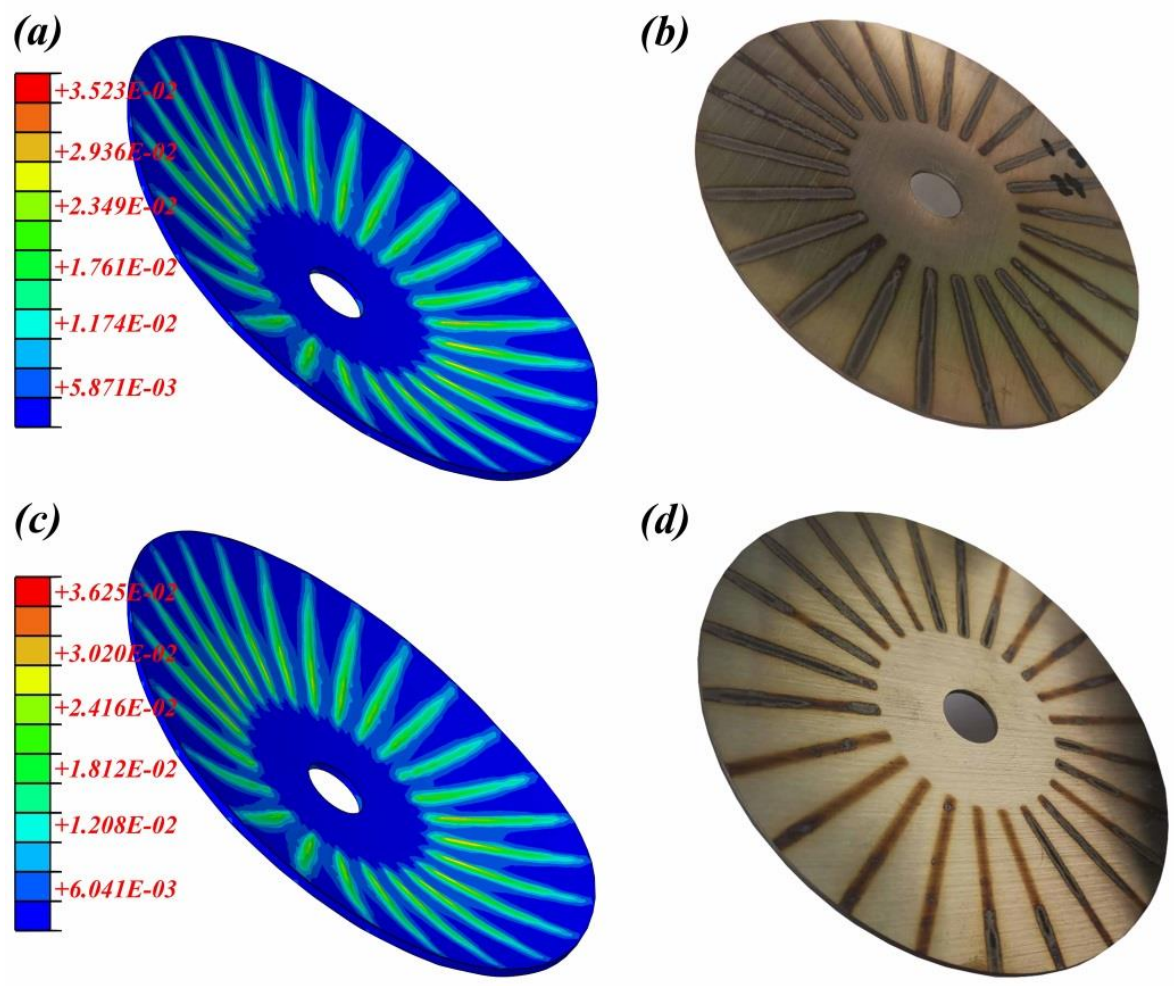

Figure 6 Numerical simulation and experimental results. (a) Numerical simulation results of strategy a ;(b) Experimental results of strategy a; (c) Numerical simulation results of strategy c ;(d) Experimental results of strategy c.

Figure 7 shows the comparison of the vertical displacement height of characteristic points (A $\sim \mathrm{H})$ at the edge of the formed plate between the numerical simulation and the experimental results data, the maximum error is $3.0 \%$, the minimum error is $0.86 \%$. The experimental data are slightly greater than the numerical simulation data, which may be caused by the differences in thermal physical properties parameters such as thermal expansion coefficient, and the numerical simulation data are highly consistent with the experimental data, which can fully show that the established numerical model is reliable. Table 2 shows the laser process parameters. 

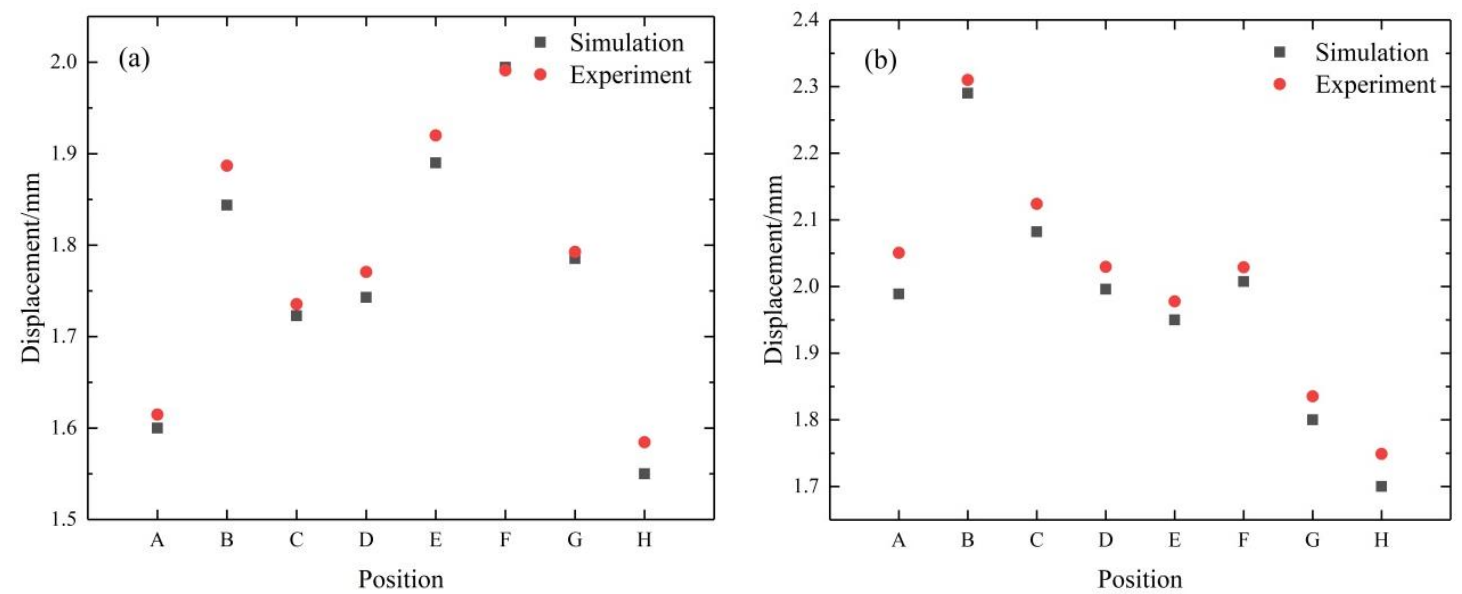

Figure 7 Comparison of numerical simulation result and experimental result.(a) Strategy(a);(b)

Strategy(c).

Table.2 Laser process parameters

\begin{tabular}{ccccc}
\hline $\begin{array}{c}\text { Laser power } \\
\mathrm{P} / \mathrm{W}\end{array}$ & $\begin{array}{c}\text { Radius of laser spot } \\
\mathrm{D} / \mathrm{mm}\end{array}$ & $\begin{array}{c}\text { scanning speed } \\
\mathrm{V} / \mathrm{mm} \cdot \mathrm{S}^{-1}\end{array}$ & $\begin{array}{c}\text { Number of scanning } \\
\mathrm{N}\end{array}$ & Scanning strategy \\
\hline 600 & 6 & 15 & 1 & Strategy(a) \\
600 & 6 & 15 & 1 & Strategy(c) \\
\hline
\end{tabular}

\section{Result and discussion}

4.1 Effect of heating line scanning direction on bowl surface forming

Figure 8 shows the experimental values of the edge height of the plate in different scanning directions, and the abscissa in the figure indicates the angle value after unfolding the circular plate, where Figure 8 (a) shows the value under the sequential scanning strategy and Figure 8 (b) shows the value under the symmetrical scanning strategy. The laser parameters were kept constant during the forming process, only the laser scanning direction was changed, and the laser process parameters are shown in Table 3.
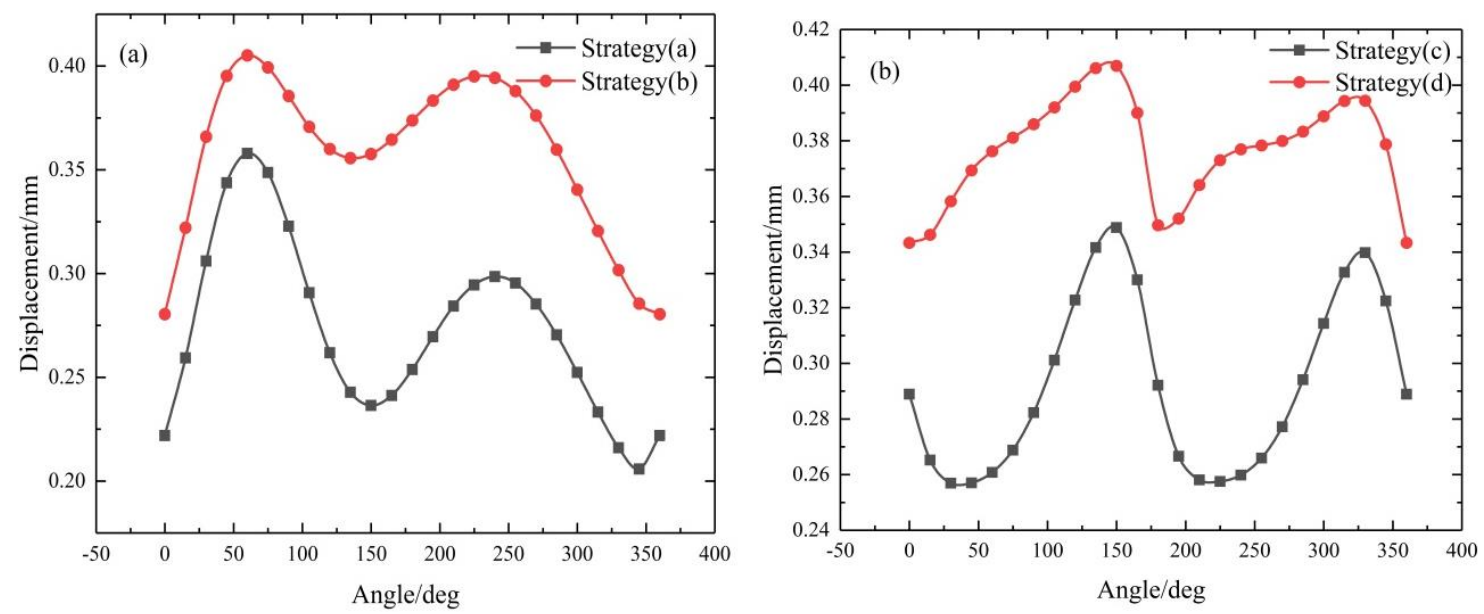

Figure 8 Influence of scanning direction of heating line on forming. (a) Sequential scanning strategy;(b) 


\section{Symmetric scanning strategy.}

It was found that when the scanning direction of laser heating line was inside to outside, the bending degree of plate was larger. The average displacement heights of edge of scanning strategy (a) and strategy (c) were $0.27 \mathrm{~mm}$ and $0.29 \mathrm{~mm}$, respectively, and the average displacement heights of edge of strategy (b) and strategy (d) were $0.35 \mathrm{~mm}$ and $0.38 \mathrm{~mm}$, respectively. Due to the difference in the temperature distribution on the heating line under the two scanning strategies, Figure 9 shows the temperature distribution on the heating line under the two scanning strategies, Figure 9 (a) shows the first heating line in the forming process, in which, points $\mathrm{M}, \mathrm{N}$ represent the starting point or end point under the two scanning strategies. When the scanning direction is outside to inside, point $\mathrm{N}$ is the starting point of heating line, $\mathrm{M}$ is the end point of heating line. When the scanning line direction is inside to outside, point $\mathrm{M}$ is the starting point of heating line, $\mathrm{N}$ is the end point of heating line.

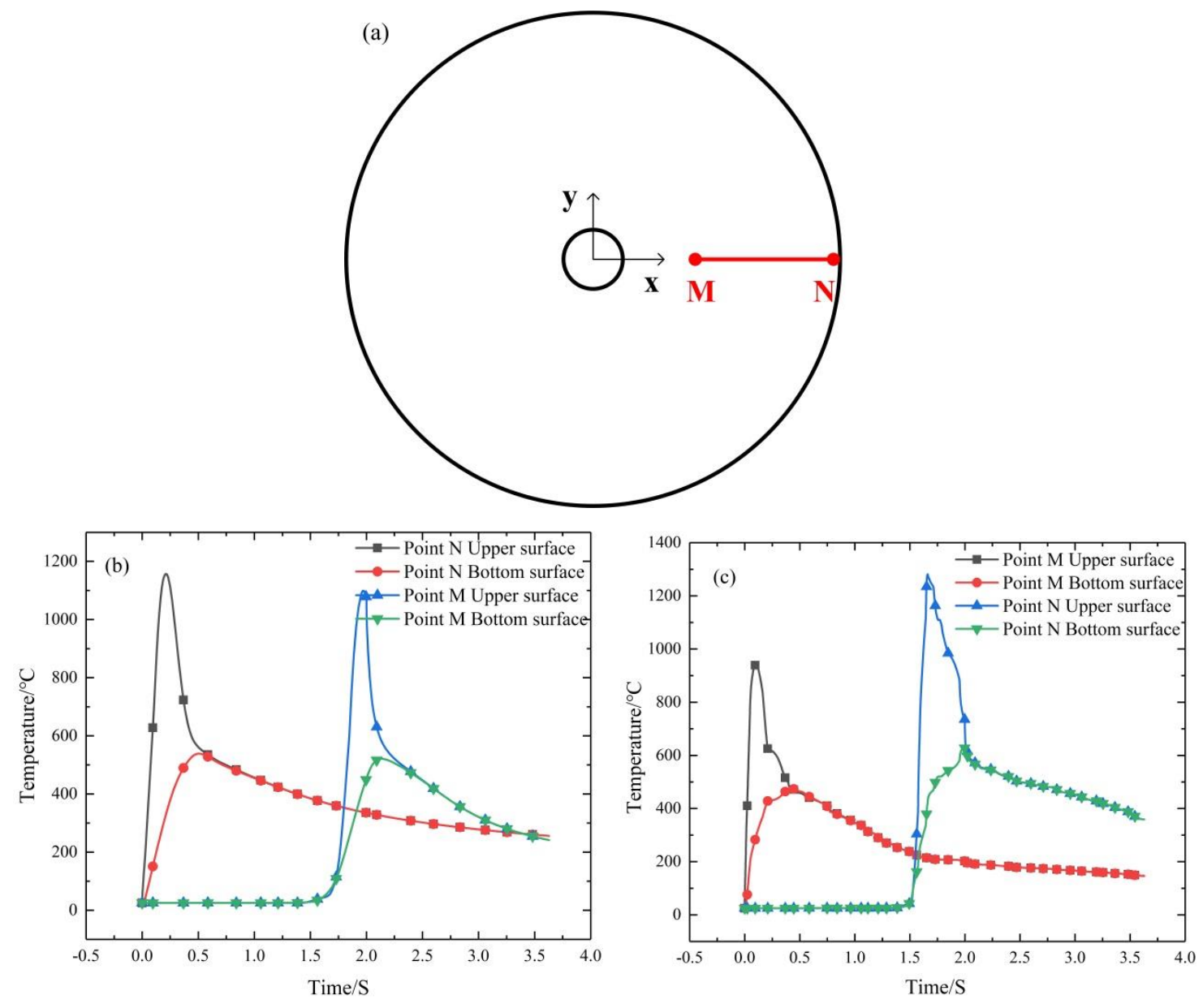

Figure 9 Temperature distribution on heating line under different scanning strategies. (a)The heating line ;(b)

Scanning direction is from the outside to the inside; (c) Scanning direction is from the inside to the outside. 
During the movement of laser along the heating path, it had a preheating effect on the front material, and there existed heat accumulation phenomenon at the end of heating path. Figure 9 (b) shows the history of temperature change at the upper and bottom surfaces of the starting end $\mathrm{M}$ and the end $\mathrm{N}$ of the heating line when the scanning direction is outside to inside. It was found in the study that the temperature at the end showed a decreasing trend while not an increasing trend. This is because the cooling material on both sides of heating line gradually increased during the inward movement of laser spot, and the heat diffused to the periphery through the way of heat conduction, which resulted in the decrease of the temperature at the end of heating line and the compressive stress of the particles on the heating line decreases, and finally resulted in the decrease of deformation. Figure 9 (c) shows the history of temperature changes at the start $\mathrm{M}$ and the end $\mathrm{N}$ of the heating line when the scanning direction is inside to outside. The temperature at the end of the heating path increases. This is result form the preheating effect of the laser spot on the front material. Moreover, during the outward movement of the laser spot, the cooling material at both sides of the heating line decreases, the heat conduction path on the plate decreases, and the temperature reaches the highest when the laser spot moves to the end of the heating path, which results in a greater compressive stress and further in turn leads to an increase in the degree of bending.

Table. 3 Laser process parameters

\begin{tabular}{ccccc}
\hline $\begin{array}{c}\text { Laser power } \\
\text { P/W }\end{array}$ & $\begin{array}{c}\text { Radius of laser spot } \\
\mathrm{D} / \mathrm{mm}\end{array}$ & $\begin{array}{c}\text { scanning speed } \\
\mathrm{V} / \mathrm{mm} \cdot \mathrm{S}-1\end{array}$ & $\begin{array}{c}\text { Number of scanning } \\
\mathrm{N}\end{array}$ & Scanning strategy \\
\hline 400 & 6 & 15 & 1 & Strategy(a) \\
400 & 6 & 15 & 1 & Strategy(b) \\
400 & 6 & 15 & 1 & Strategy(c) \\
400 & 6 & 15 & 1 & Strategy(d) \\
\hline
\end{tabular}

4.2 Effect of heating line scanning sequence on bowl surface forming

Figure 10 shows the effect of heating line scanning order on the bowl surface forming. It shows the experimental results under sequential scanning and symmetrical scanning. The scanning direction of in Figure 10 (a) is outside to inside and the scanning direction in Figure 10 (b) is inside to outside. 

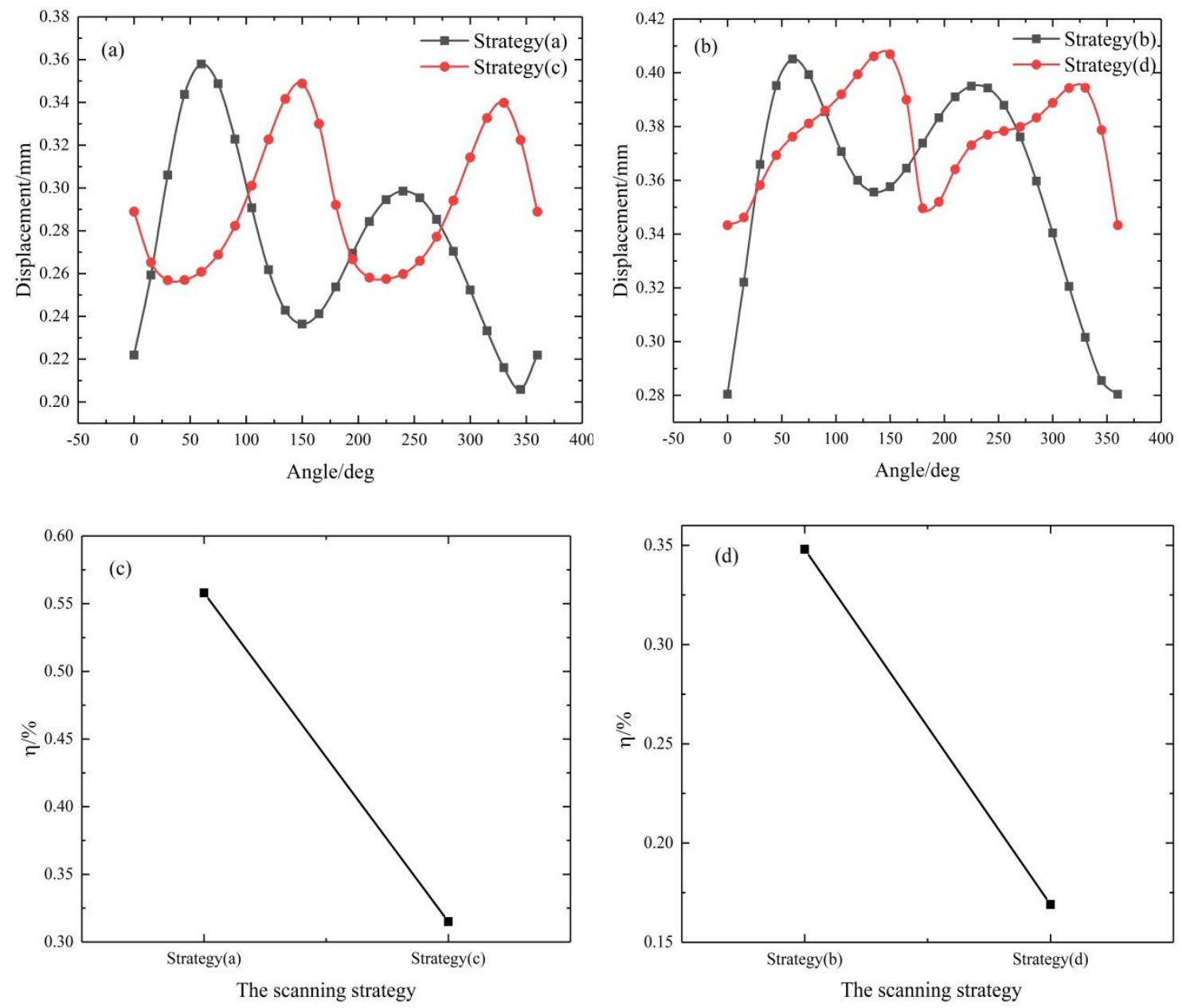

Figure 10 Influence of heating line scanning sequence on forming. (a) Scanning direction is outward and inward; (b) Scanning direction is inward and outward; (c) The relative rate of change of displacement of Strategy a and c; (d) The relative rate of change of displacement of Strategy b and d.

Under the symmetrical scanning strategy, the relative change rate of displacement decreased, and the forming accuracy was effectively controlled. It was found that the inside to outside symmetrical scanning strategy (Strategy d) could improve the forming accuracy while obtaining the bending deformation. In the symmetrical scanning mode, the two adjacent heating lines were $180^{\circ}$ apart, and the temperature distribution on the plate was more uniform, which could effectively avoid the temperature concentration phenomenon in the sequential heating strategy.

\subsection{Effect of laser power on bowl surface forming}

Figure 11 shows the effect of different laser power on the bowl surface forming. Figure 11 (a) shows the change of average height of plate edge with laser power. The displacement height of plate edge shows an increasing trend with the increase of laser power. Figure 11 (b) shows the distribution of plate edge height in the circumferential direction. The laser power has the highest 
bending degree under the working condition of $600 \mathrm{~W}$, but its displacement fluctuation amplitude along the circumferential direction is large. Figure 11 (c) shows the relative change of displacement in the circumferential direction. At the laser power of $500 \mathrm{~W}$, the relative change amplitude of plate edge displacement is the smallest, and the forming accuracy is the highest. Figure 11 (d) shows the relative change rate of displacement under different laser power. At the laser power of $500 \mathrm{~W}$, its relative change rate is $0.31 \%$.
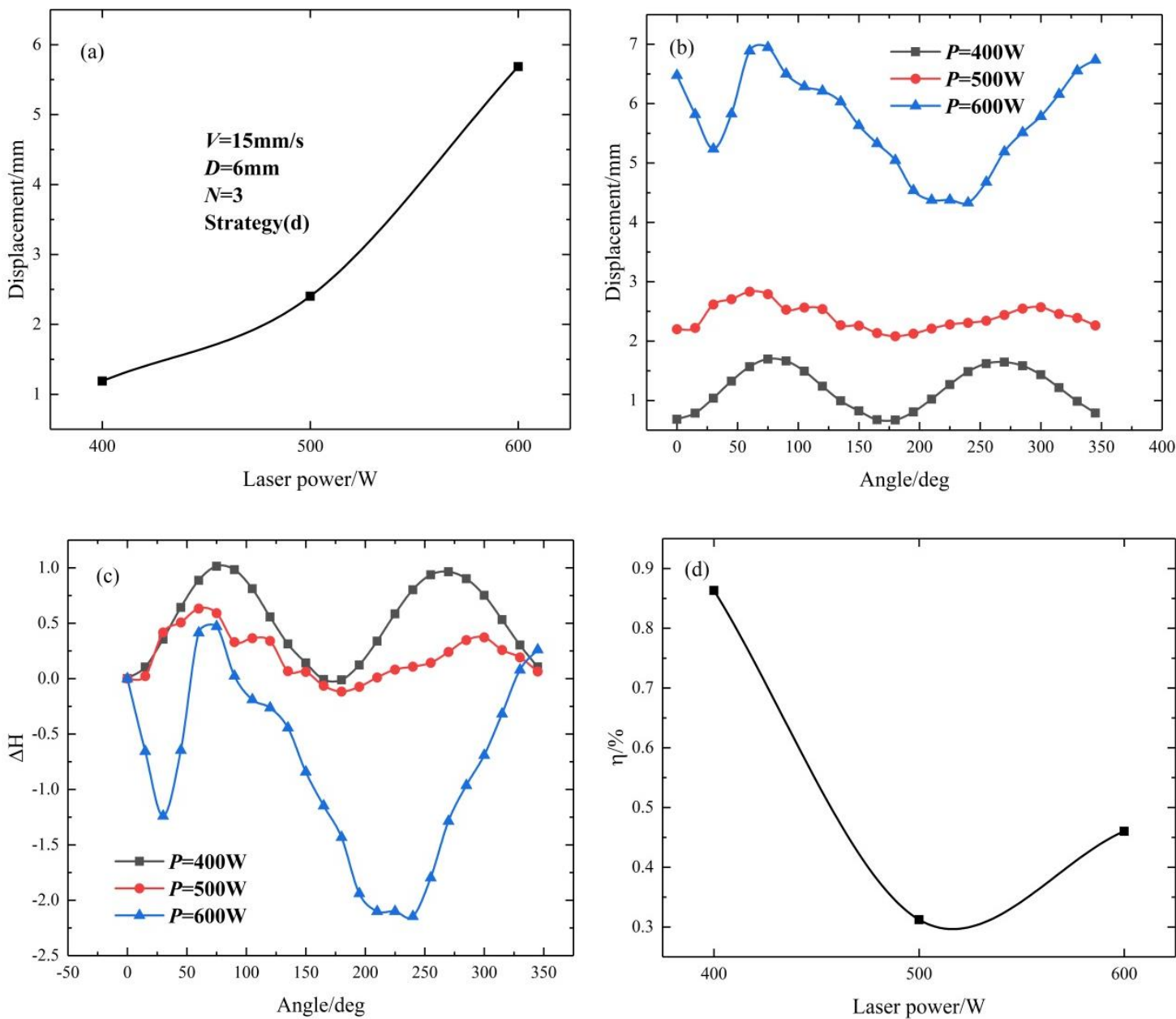

Figure 11 Influence of laser power on forming.(a) Displacement varies with laser power;(b) The height of the edge position of the plate;(c) Variation of edge position height of plate;(d) The relative rate of change under different laser power.

Table.4 Laser process parameters

\begin{tabular}{ccccc}
\hline $\begin{array}{c}\text { Laser power } \\
\text { P/W }\end{array}$ & $\begin{array}{c}\text { Radius of laser spot } \\
\mathrm{D} / \mathrm{mm}\end{array}$ & $\begin{array}{c}\text { scanning speed } \\
\mathrm{V} / \mathrm{mm} \cdot \mathrm{S}-1\end{array}$ & $\begin{array}{c}\text { Number of scanning } \\
\mathrm{N}\end{array}$ & Scanning strategy \\
\hline 400 & 6 & 15 & 3 & Strategy(d) \\
500 & 6 & 15 & 3 & Strategy(d) \\
600 & 6 & 15 & 3 & Strategy(d) \\
\hline
\end{tabular}




\subsection{Effect of heating line length on forming}

Figure 12 shows the experimental results of the average height value of the plate edge under different heating line lengths. It is found that when the heating line length is less than $20 \mathrm{~mm}$, the average displacement height of the edge position shows a linear increasing trend with the increase of the heating line length. It is due to the increase of the heating line length, the increase of the heat flux on the plate surface, and the low thermal conductivity of the stainless steel material, the increase of the temperature gradient on the upper and lower surfaces of the plate, and the plastic deformation ability of the plate is stronger, and finally, increased deformation induction. When the length of heating line exceeded $20 \mathrm{~mm}$, the edge height of the plate decreased, which was because the temperature gradient of the upper and lower surfaces of the plate decreases after the heat flow on the plate exceeded a certain value, resulting in a decrease in the deformation of the plate. Figure 12 (b) shows the plate forming accuracy at different heating line lengths, and the formed plate edge height is the most uniform at a heating line length of $20 \mathrm{~mm}$, with a relative change rate of $0.099 \%$ and the highest forming accuracy. Figure 13 shows the experimental results at different heating line lengths.
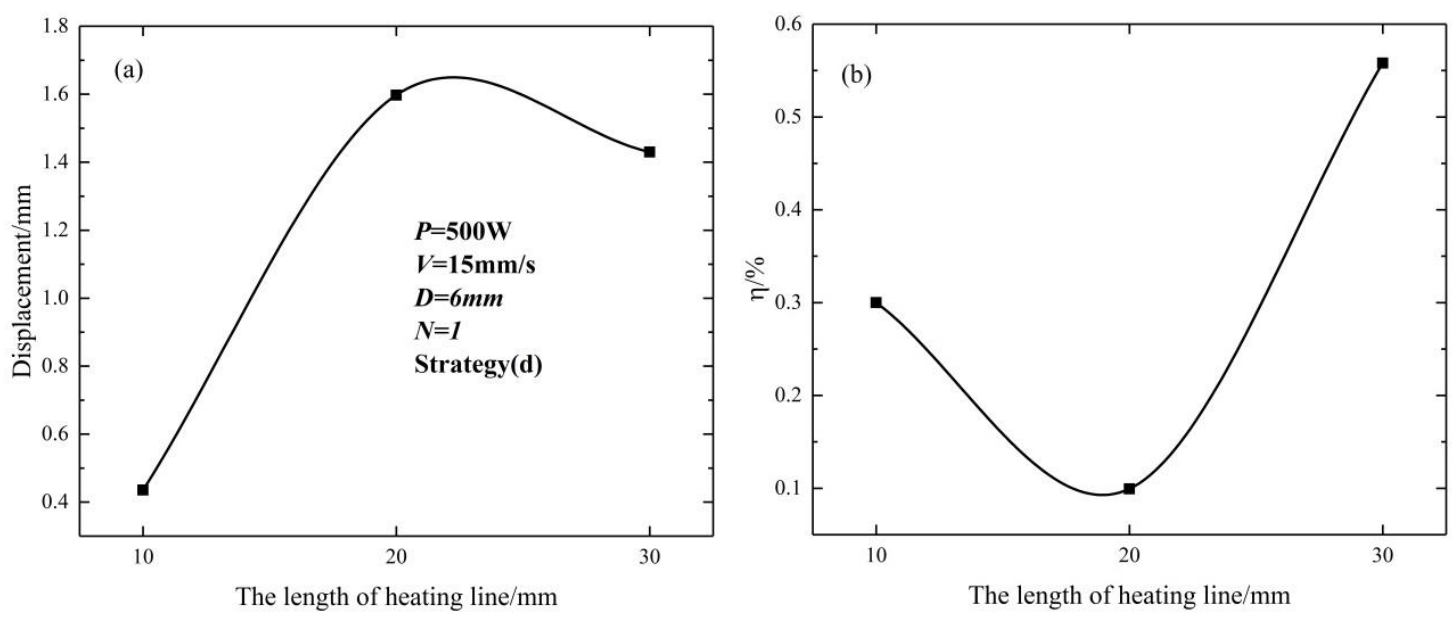

Figure 12 Influence of length of heating line on forming. (a) Displacement varies with the length of heating line ;(b) The relative rate of change under different length of heating line. 
(a)

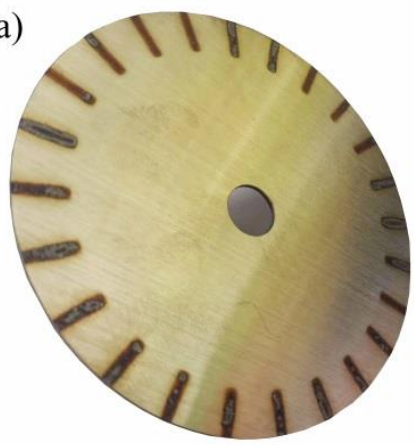

$L=10$ (b)

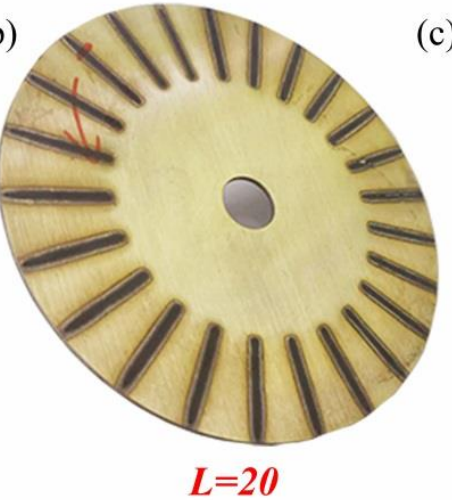

(c)

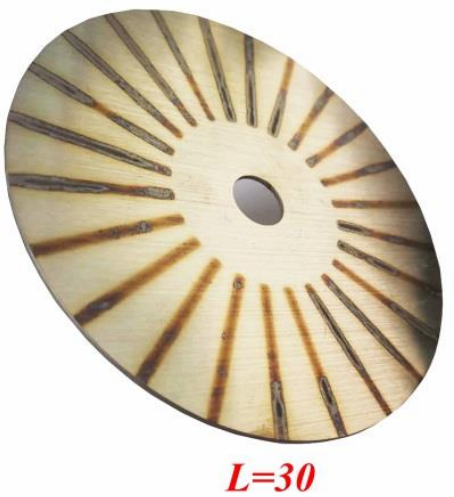

Figure 13 Experimental results of different heating line lengths.

4.5 Effect of laser scanning speed on bowl surface forming

Figure 14 shows the experimental results of plate edge displacement at different scanning speeds. The plate deformation shows a decreasing trend with the increase of scanning speed. When the scanning speed increased, the heat absorption per unit length on the plate surface decreased, and the temperature gradient formed in the plate thickness direction was small, so the deformation showed a decreasing trend. When the scanning speed exceeded $20 \mathrm{~mm} / \mathrm{s}$, which was faster, therefore, there internal temperature of the material was low and the yield strength was relatively high, which resulted to small difference between the plastic compressive strain on the upper surface of the plate and the plastic tensile strain on the bottom surface, therefore, the plate deformation degree was greatly reduced. When the scanning speed was less than $10 \mathrm{~mm} / \mathrm{s}$, the plate surface temperature was relatively high, which was easily result to melting phenomenon.

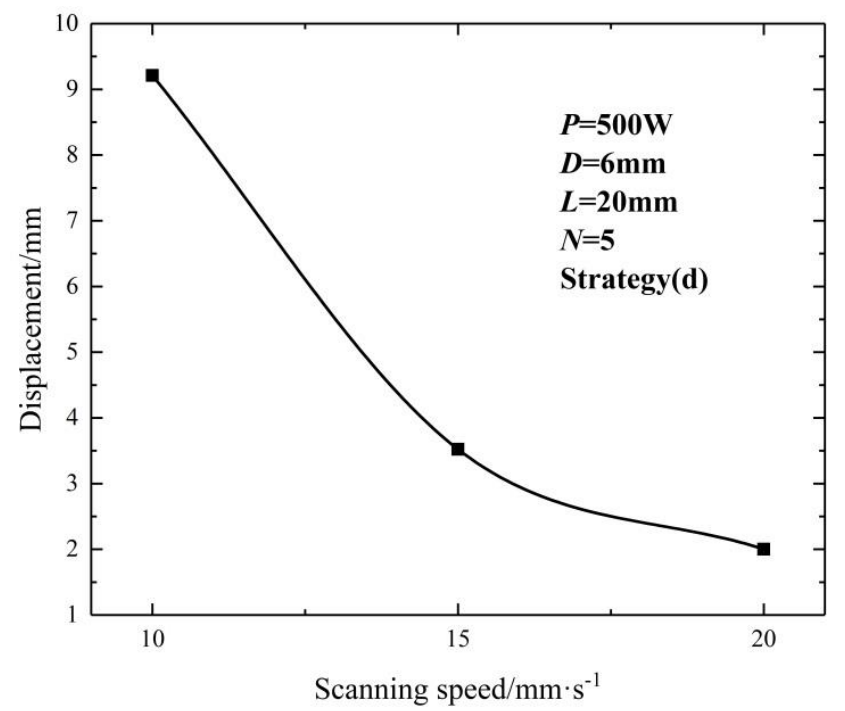

Figure 14 Influence of scanning speed on forming.

4.6 Effect of laser scanning times on bowl surface forming 
Figure 15 shows the relationship between the plate deformation and the number of laser repeated scans. When the number of repeated scans is less than 5 , the plate forming amount approximately increases linearly with the increase of heating times. The reason lies in the large temperature gradient on the upper and bottom surfaces of plates result from the long interval between repeated scans of plates. On the other hand, after more than 3 heating times, the internal temperature of plates increases and the yield strength of plates decreases, so the growth rate of deformation amount remains high. When the number of repeated scans is greater than 5 , the bottom surface temperature of plates increases rapidly, the temperature gradient on the upper and bottom surfaces of plates decreases, and the growth rate of plate deformation amount decreases. When the number of repeated scans is more than 7 , the plate deformation amount tends to be stable, and the growth rate of deformation amount decreases significantly, which may be related to the thickening of scanning path and strain enhancement.

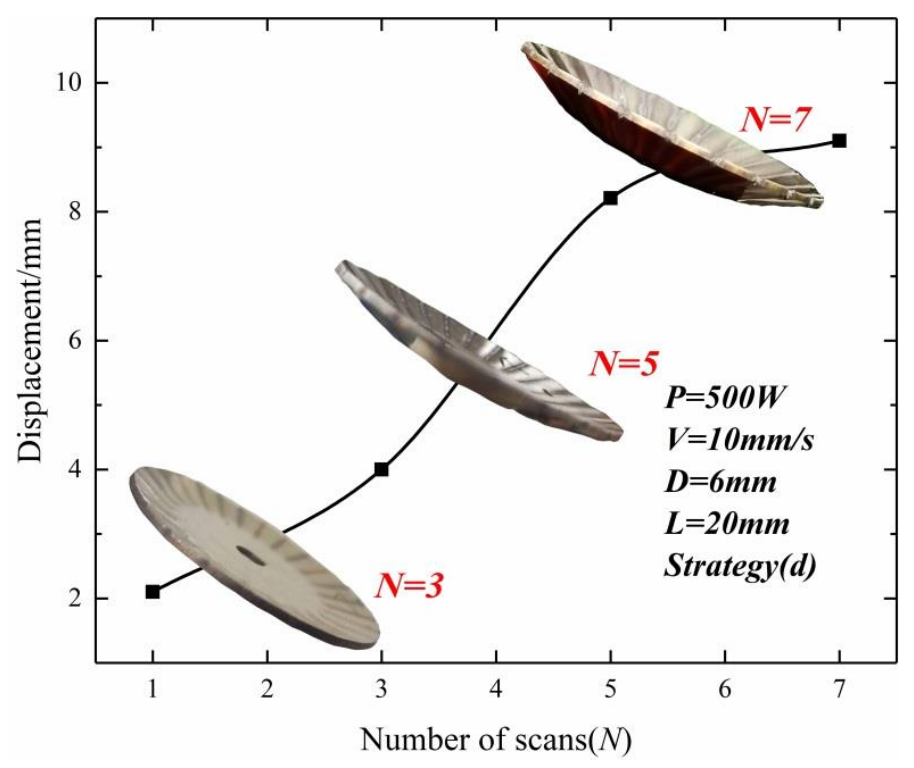

Figure 15 Influence of number of scans on forming.

\section{Conclusion}

In this paper, the effect of radial scanning strategy on the bowl surface forming of three-layer stainless steel composite plate is studied. The three-dimensional thermodynamic coupling model of three-layer stainless steel composite plate is established. The effects of scanning mode and laser parameters on the deformation amount and forming accuracy of bowl surface are studied. Moreover, the model is verified by experiments.

It is found that the optimal strategy for three-dimensional bowl surface forming is inside to 
outside symmetric scanning strategy (Strategy d); the deformation increases with the increase of laser power, while its forming accuracy begins to decrease when the laser power reaches $600 \mathrm{~W}$; when the heating line length is less than $20 \mathrm{~mm}$, the deformation is linear with the heating line length, and decreases when the heating line reaches $30 \mathrm{~mm}$; the plate deformation decreases with the increase of scanning speed; when the number of repeated scans is less than 5 , the deformation is approximately linear with the number of repeated laser scans; the optimal forming process conditions for stainless steel composite plates are: $P=500 \mathrm{~W}, V=10 \mathrm{~mm} / \mathrm{s}, L=20 \mathrm{~mm}, N=7$.

\section{Ethical Approval and Consent to Participate:}

Not applicable.

\section{Consent to participate:}

Not applicable.

\section{Consent to Publish:}

Not applicable.

\section{Authors Contributions:}

Xiaogang Wang: Conceptualization, Methodology, Software, Investigation, Writing - Original Draft.

Yongjun Shi: Validation, Formal analysis, Visualization, Software.

Yankuo Guo: Validation, Formal analysis, Visualization.

Qin Wang: Methodology, Software, Investigation.

\section{Availability of data and materials:}

All data generated or analysed during this study are included in this published article.

\section{Funding:}

National Natural Science Foundation of China (No. 51175515), Petro-China Innovation Foundation (Grant 2017D-5007-0307), and the Fundamental Research Funds for the Central Universities (No. 18CX05004A).

\section{Competing Interests:}

The authors declared that they have no conflicts of interest to this work.

\section{References:}

[1]Chakraborty S S , More H , Nath A K . Laser forming of a bowl shaped surface with a stationary laser beam[J]. Optics and Lasers in Engineering, 2016, 77(FEB.):126-136.

[2] Gisario A, Barletta M . Laser forming of glass laminate aluminium reinforced epoxy (GLARE): On the role of 
mechanical, physical and chemical interactions in the multi-layers material[J]. Optics and Lasers in Engineering, 2018, 110(NOV.):364-376.

[3] Abolhasani D, Seyedkashi S M H , Gollo M H, et al. Effects of Laser Beam Parameters on Bendability and Microstructure of Stainless Steel in Three-Dimensional Laser Forming[J]. Applied Sciences, 2019, 9(20):4463.

[4] Bucher T , Zhang M , Chen C J , et al. Laser Forming of Metal Foam Sandwich Panels: Effect of Panel Manufacturing Method[C]// ASME 2019 14th International Manufacturing Science and Engineering Conference. 2019.

[5] Yu G, Anderson R J , Maekawa T, et al. Efficient simulation of shell forming by line heating[J]. International Journal of Mechanical Sciences, 2001, 43( 10):2349-2370.

[6]Kotobi M , Mansouri H , Honarpisheh M . Investigation of laser bending parameters on the residual stress and bending angle of St-Ti bimetal using FEM and neural network[J]. Optics \& Laser Technology, 2019, 116:265-275.

[7]Kalvettukaran P, Das S, Marimuthu S, et al. Increment in laser bending angle by forced bottom cooling[J]. International Journal of Advanced Manufacturing Technology, 2018, 94(5-8):2137-2147.

[8]Rattan A, Jasra Y, Saxena R K . Prediction of bending behavior for laser forming of lime coated plain carbon steel using finite element method[J]. Materials Today: Proceedings, 2020, 28.

[9]Biplab, Das, Pankaj, et al. Effect of operating parameters on plate bending by laser line heating[J]. Proceedings of the Institution of Mechanical Engineers Part B Journal of Engineering Manufacture, 2017.

[10] Shi Y, Yao Z , Shen H, et al. Research on the mechanisms of laser forming for the metal plate[J]. International Journal of Machine Tools \& Manufacture, 2006, 46(12-13):1689-1697.

[11]Tavakoli A , Naeini H M, Roohi A H , et al. Codification of scan path parameters and development of perimeter scan strategies for 3D bowl-shaped laser forming[J]. Optics \& Laser Technology, 2018, 98:121-133.

[12]Gisario A, Barletta M, Venettacci S , et al. Progress in Tridimensional (3d) Laser Forming of Stainless Steel Sheets[J]. Lasers in Manufacturing\&Materials Processing, 2015.

[13]Shahabad S I, Naeini H M , Roohi A H, et al. Experimental investigation of laser forming process to produce dome-shaped products[J]. International Journal of Advanced Manufacturing Technology, 2016.

[14]Wang X , Shi Y, Guo Y , et al. Laser curve scanning forming process of laminated metal composite plate[J]. Materials \& Design, 2020, 191:108614-.

[15] Wenhao, Zhang, Huixia, et al. Experimental investigation on the formation behavior for three-layer metal sheets under laser high speed flexible micro-forming $[\mathrm{J}]$. The International Journal of Advanced Manufacturing Technology, 2017, 93(9-12):3149-3157.

[16] Bucher T, Young A, Zhang M, et al. Thermally Induced Mechanical Response of Metal Foam During Laser Forming[J]. Journal of Manufacturing Science \& Engineering, 2018.

[17] Chen, Chang, Jun, et al. Experimental and Numerical Investigation of Laser Forming of Closed-Cell Aluminum Foam[J]. Journal of manufacturing science and engineering: Transactions of the ASME, 2016, 138(2). 


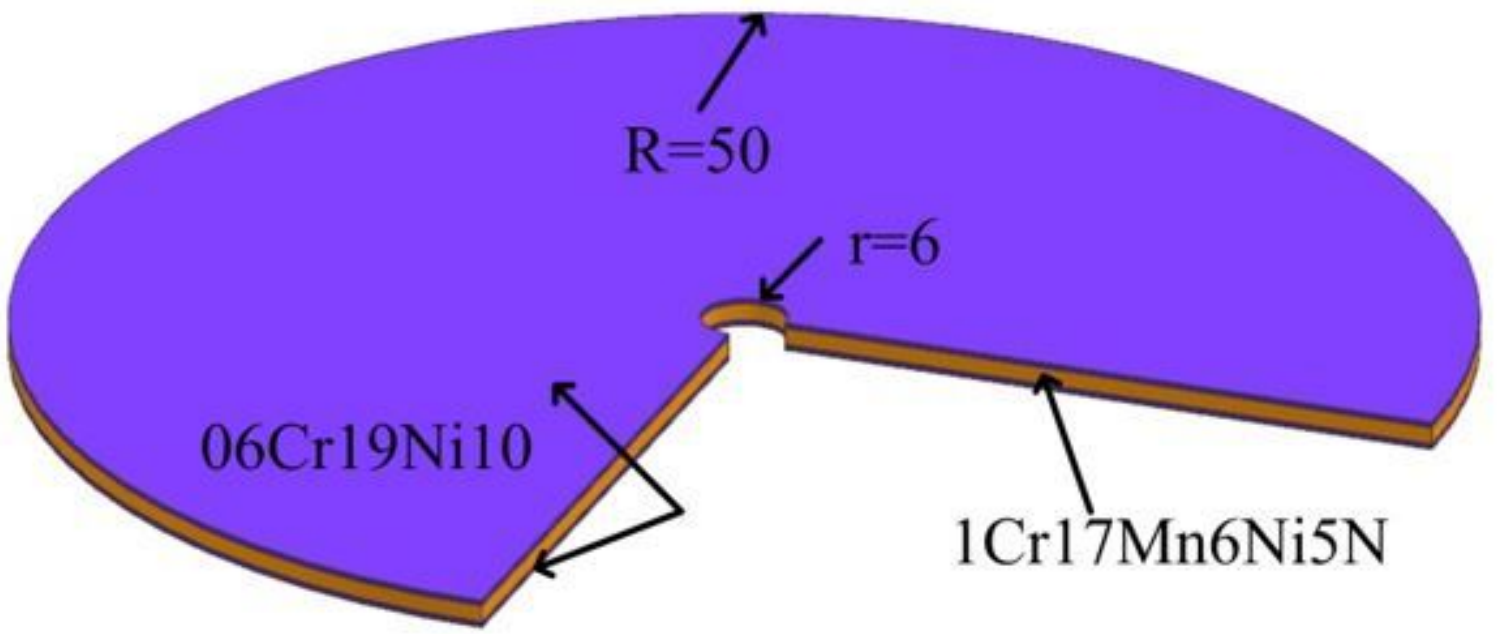

Figure 1

Schematic of Simulation Model
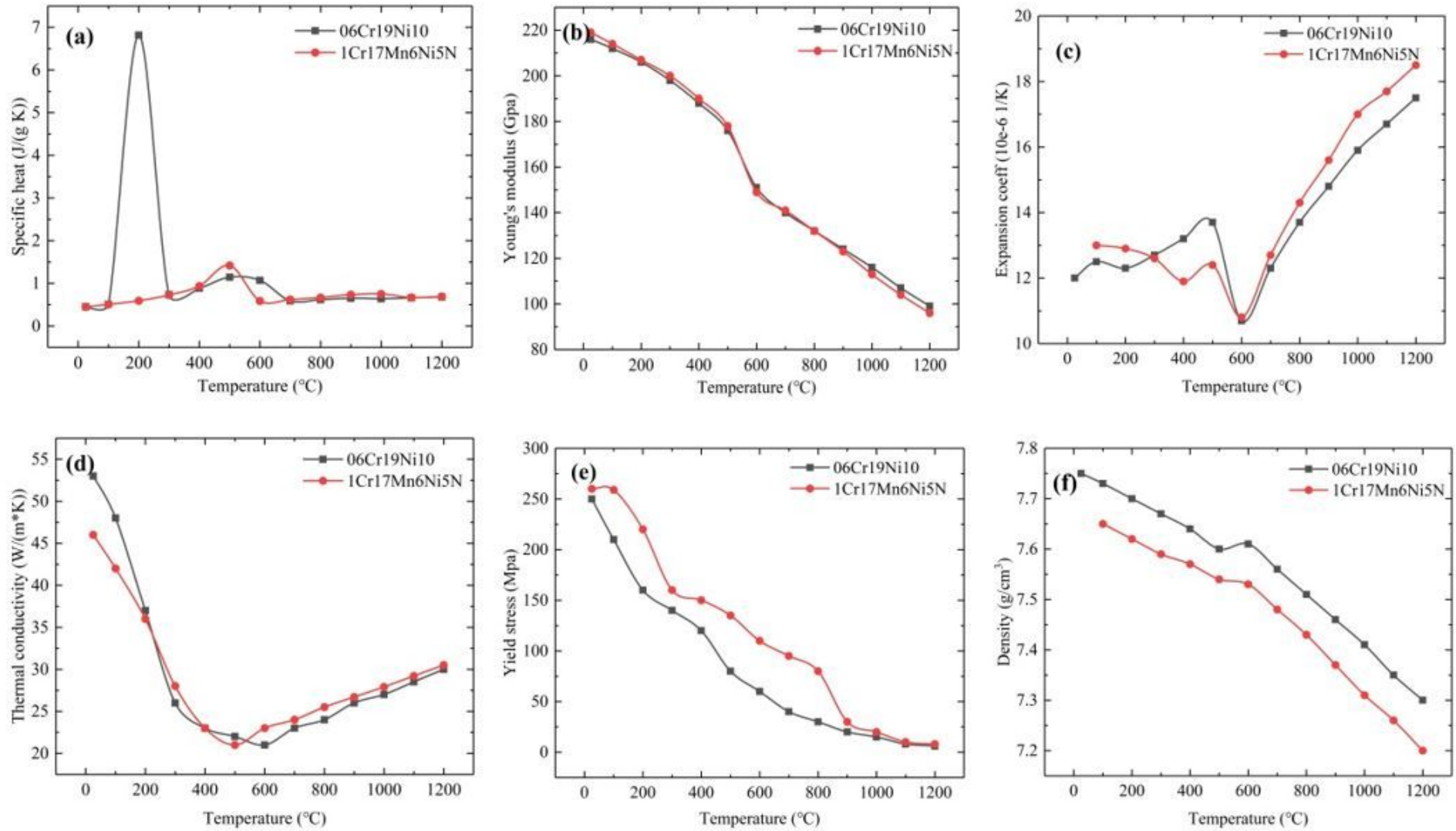

Figure 2

Thermophysical parameters of laminated stainless steel plate. 


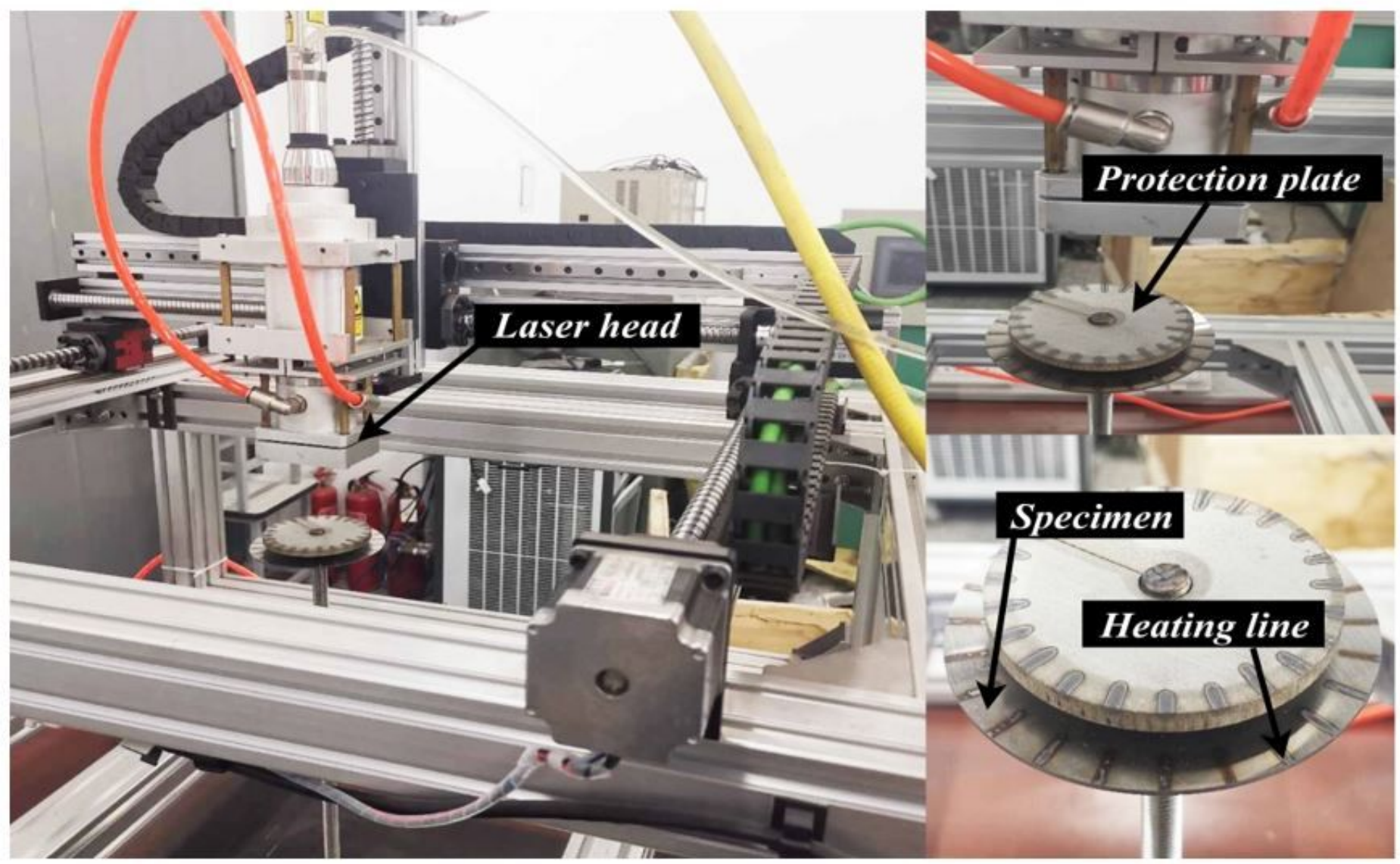

Figure 3

Experimental set-up of laser forming 


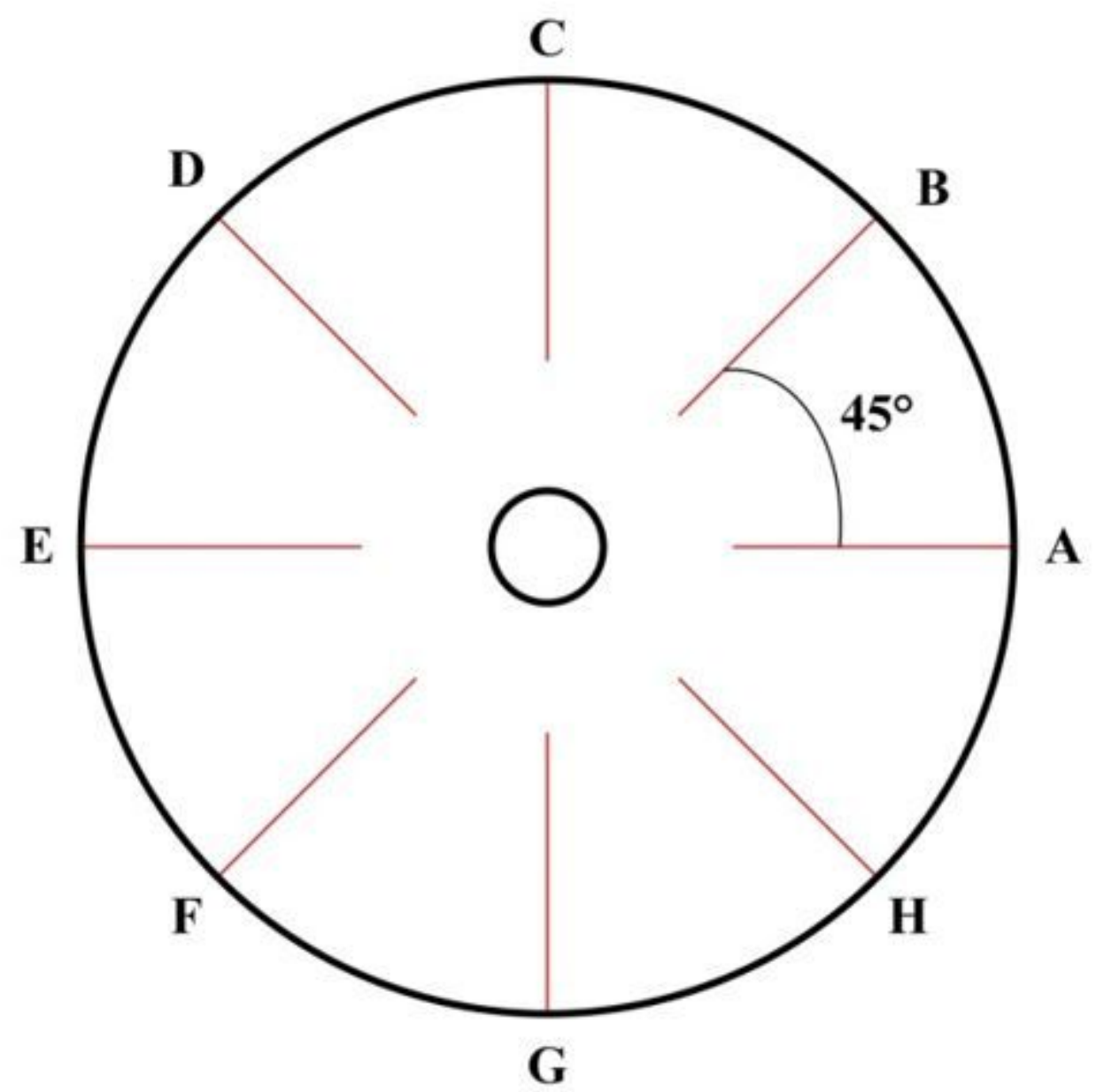

Figure 4

Diagram of feature points of plate 

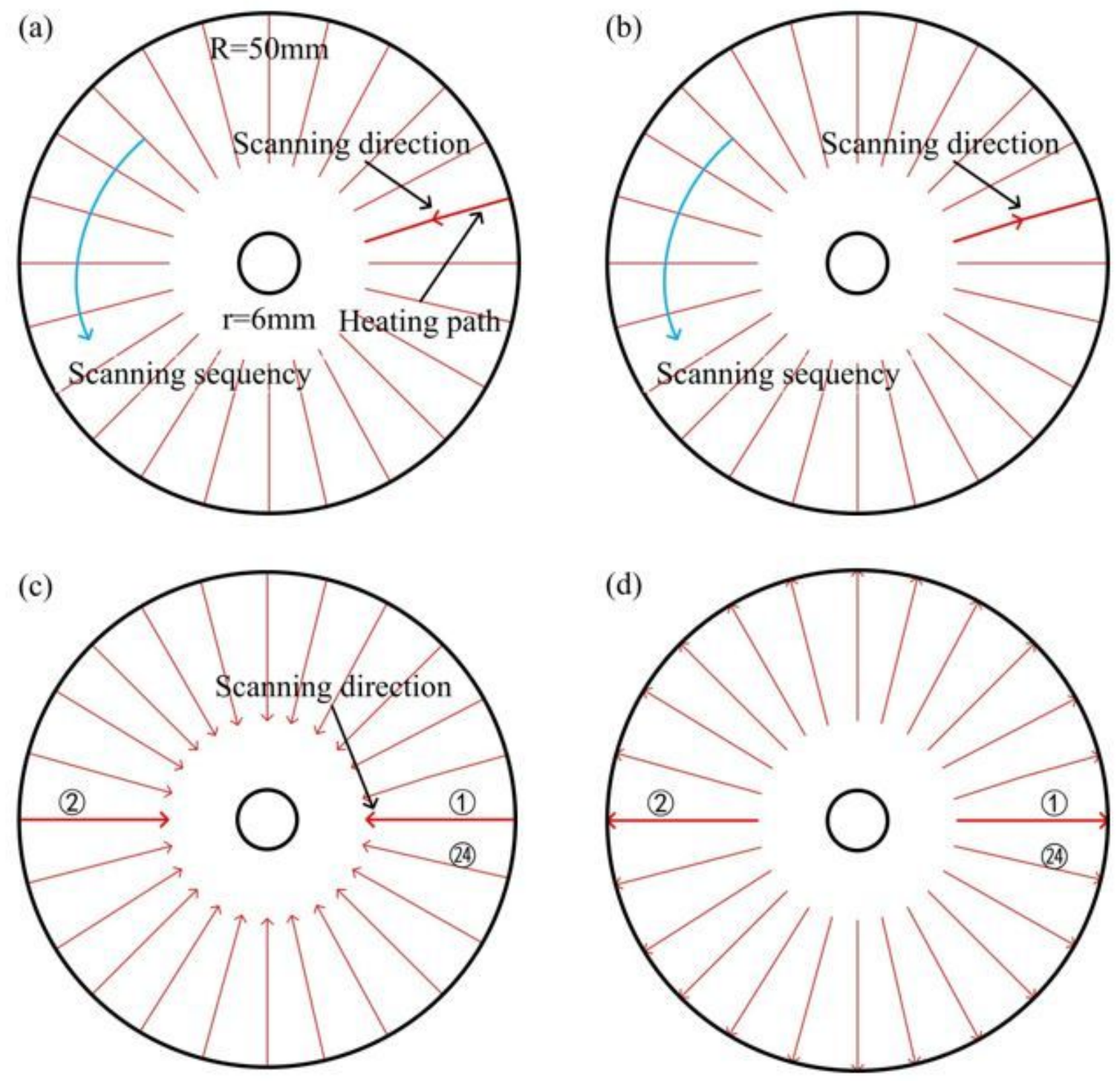

Figure 5

Diagram of laser scanning strategy. (a) Scanning strategy a;(b) Scanning strategy b;(c) Scanning strategy;(d) Scanning strategy 

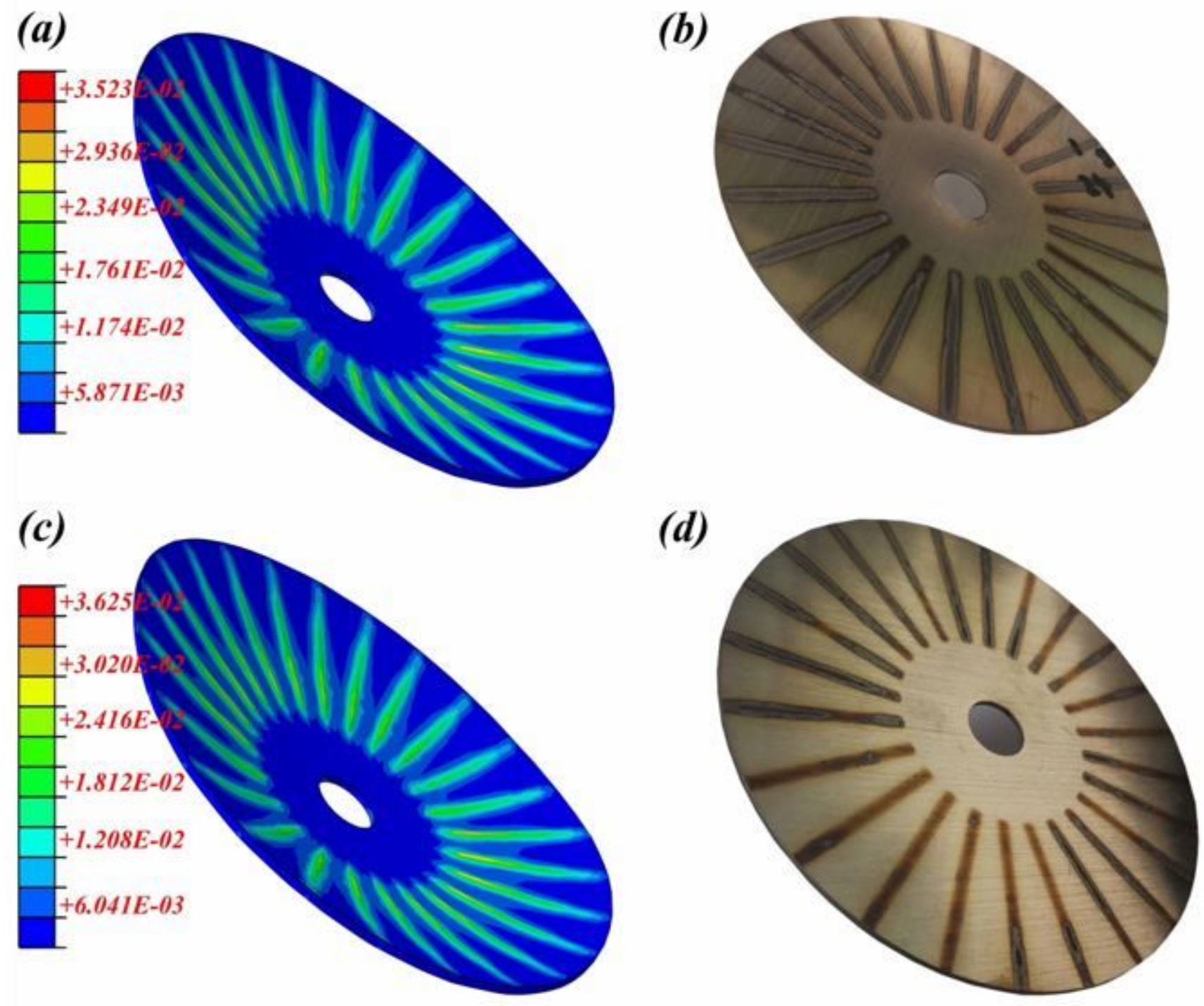

Figure 6

Numerical simulation and experimental results. (a) Numerical simulation results of strategy a ;(b) Experimental results of strategy a; (c) Numerical simulation results of strategy $c$;(d) Experimental results of strategy c. 

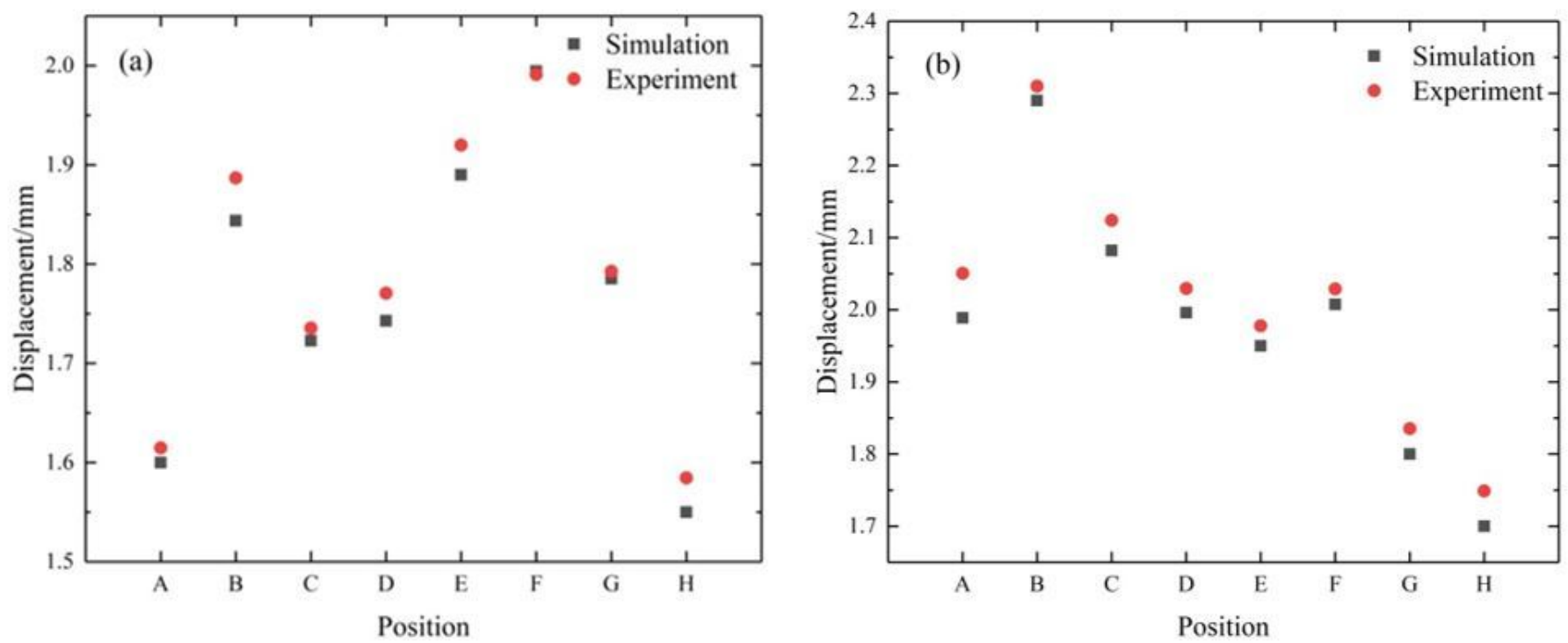

Figure 7

Comparison of numerical simulation result and experimental result.(a) Strategy(a);(b) Strategy(c).
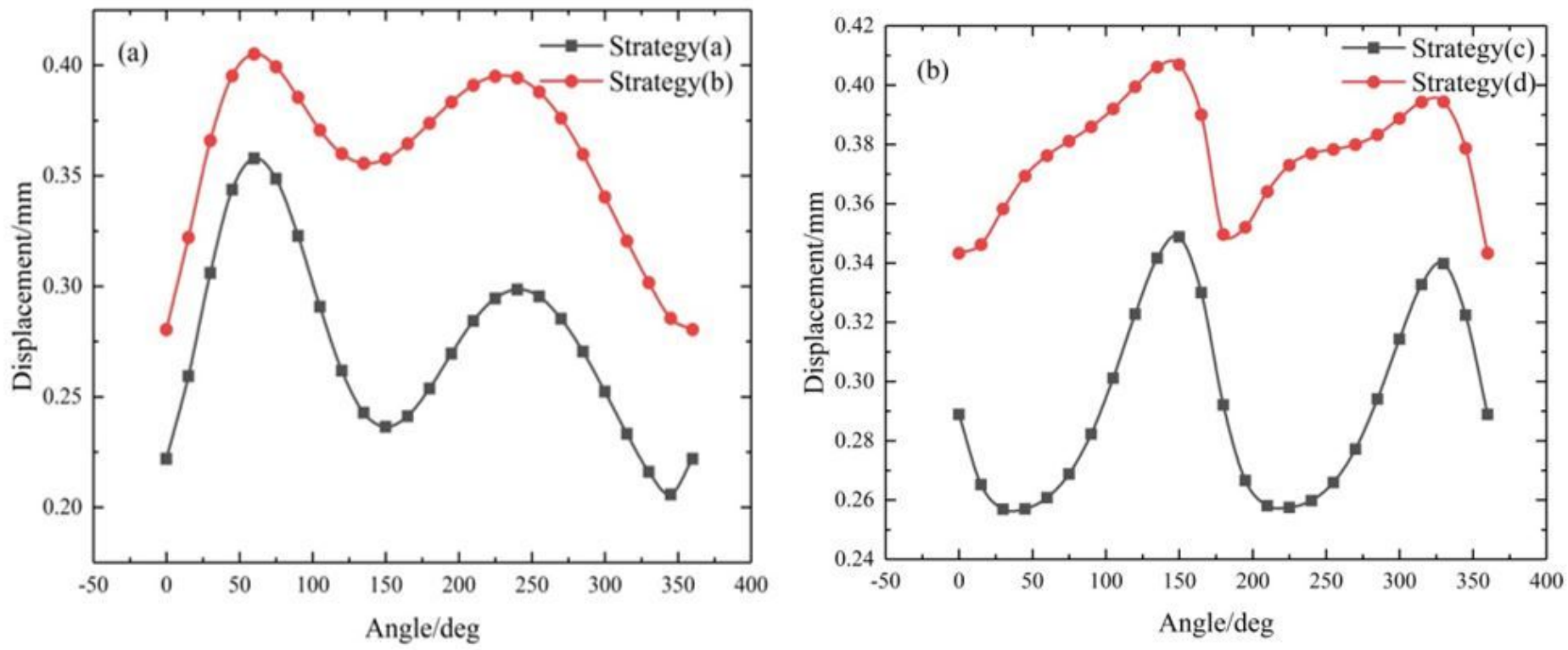

Figure 8

Influence of scanning direction of heating line on forming. (a) Sequential scanning strategy;(b) Symmetric scanning strategy. 

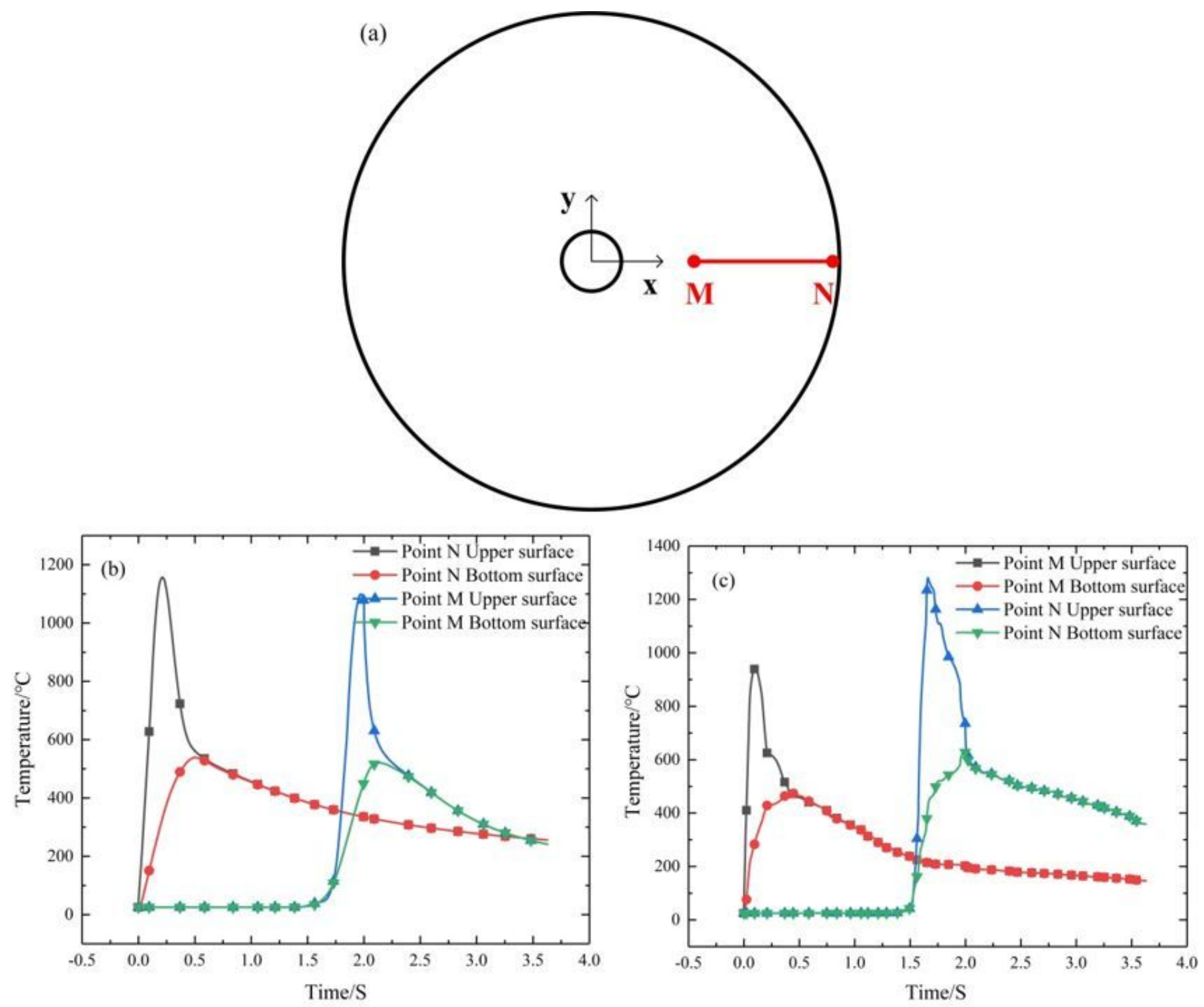

Figure 9

Temperature distribution on heating line under different scanning strategies. (a)The heating line;(b) Scanning direction is from the outside to the inside; (c) Scanning direction is from the inside to the outside. 

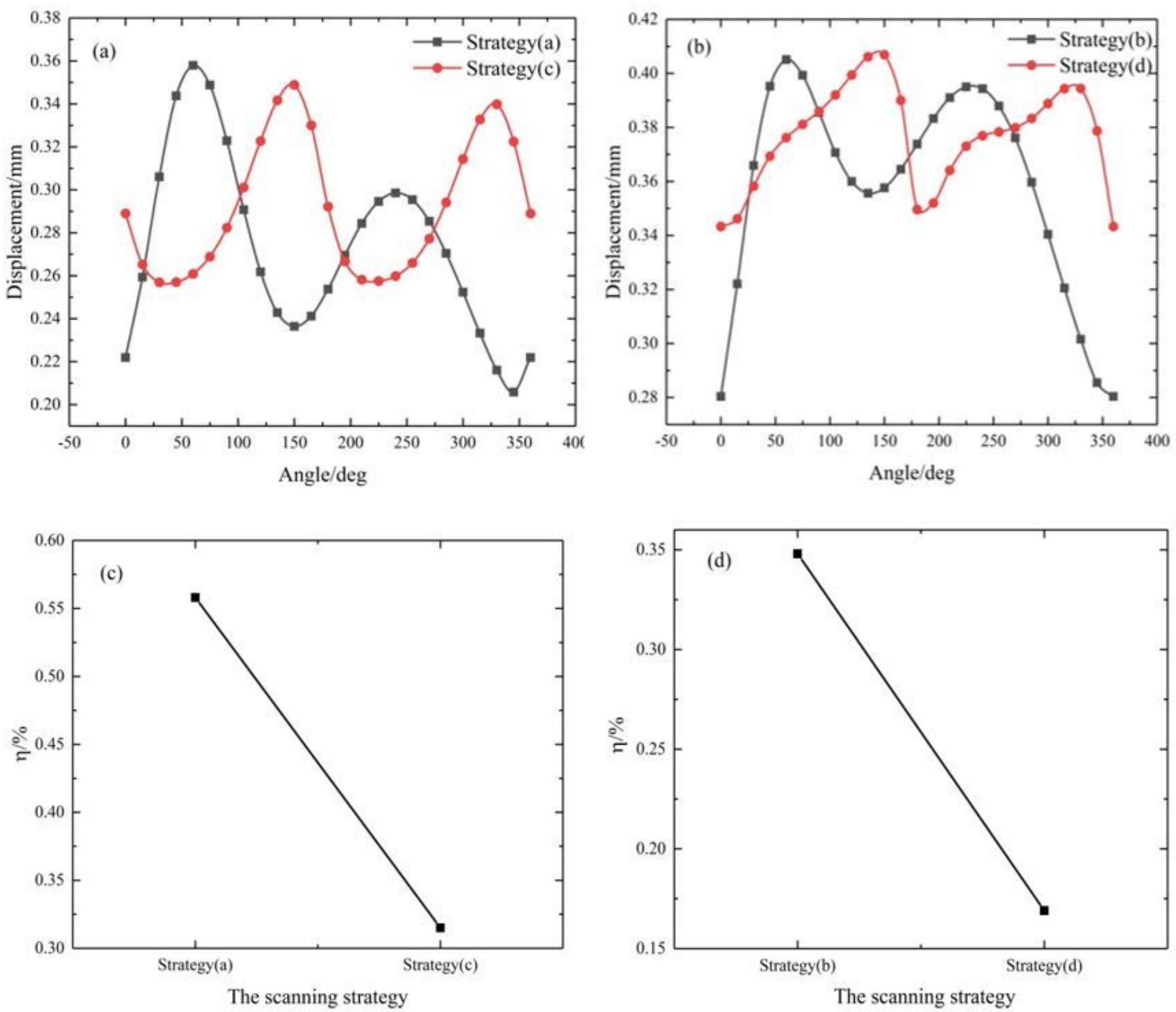

Figure 10

Influence of heating line scanning sequence on forming. (a) Scanning direction is outward and inward; (b) Scanning direction is inward and outward; (c) The relative rate of change of displacement of Strategy a and c; (d) The relative rate of change of displacement of Strategy b and d. 

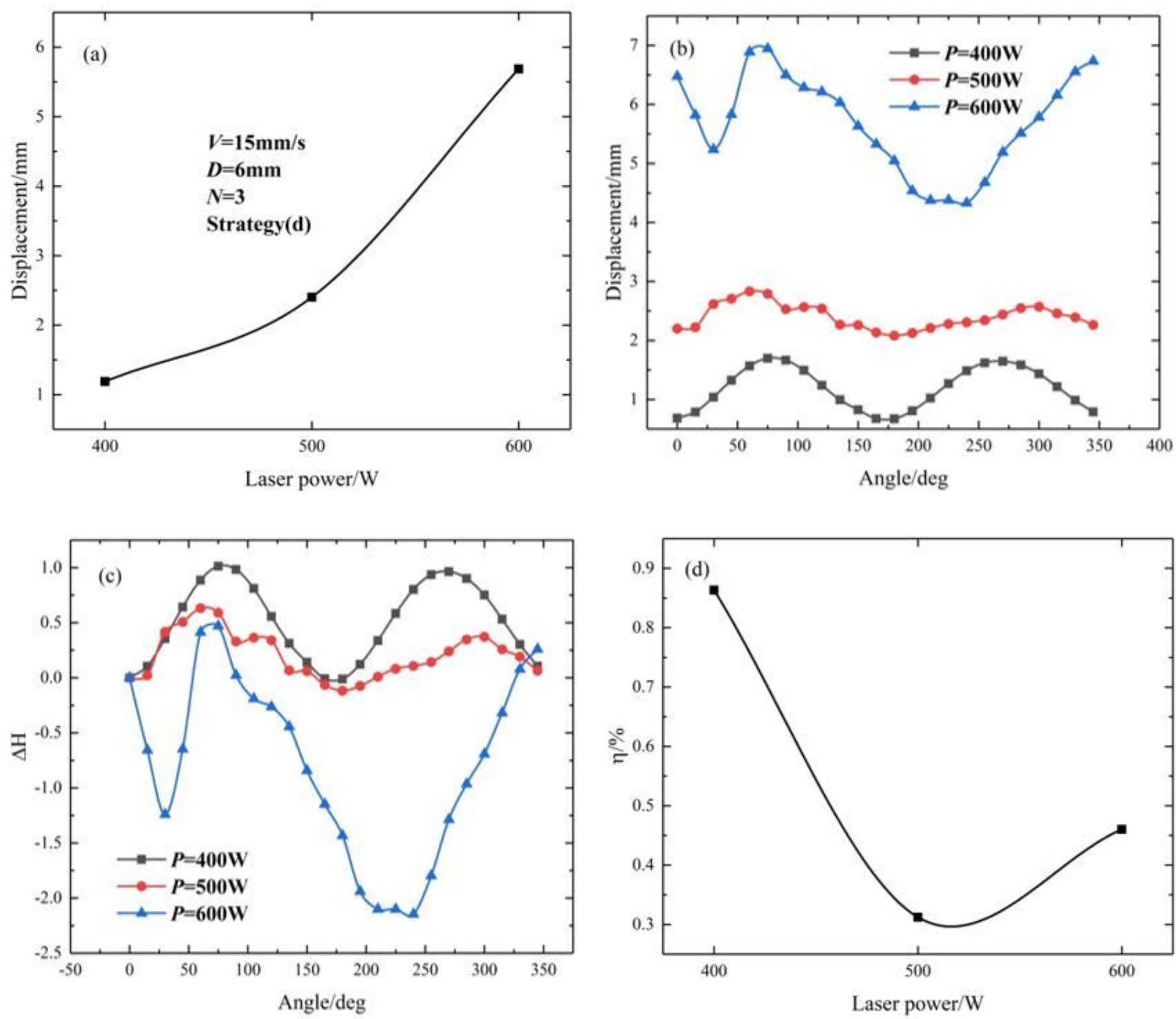

Figure 11

Influence of laser power on forming.(a) Displacement varies with laser power;(b) The height of the edge position of the plate;(c) Variation of edge position height of plate;(d) The relative rate of change under different laser power. 

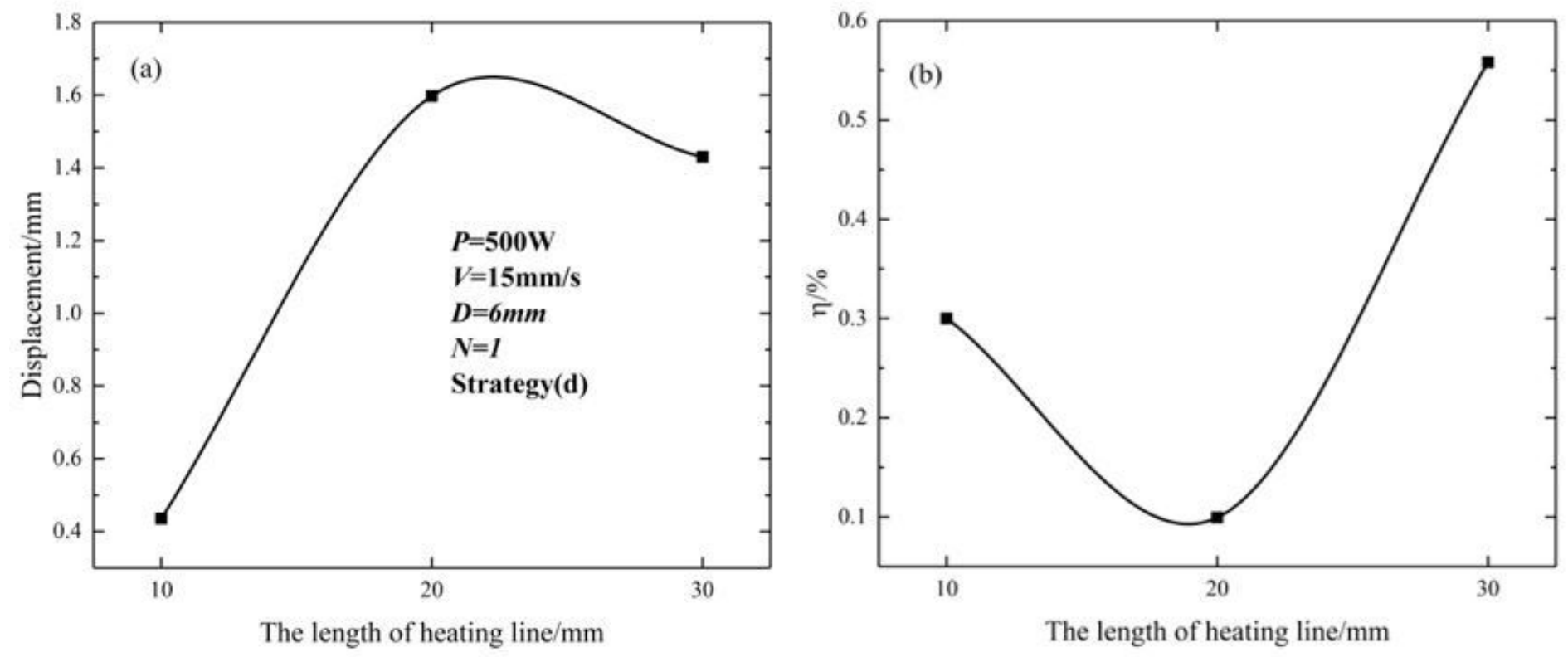

Figure 12

Influence of length of heating line on forming. (a) Displacement varies with the length of heating line ;(b) The relative rate of change under different length of heating line.

(a)

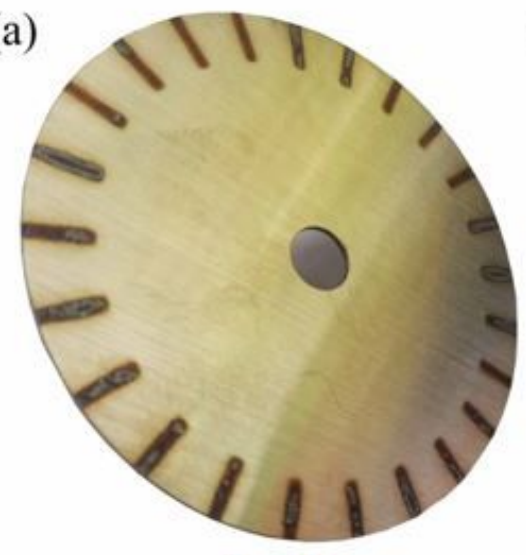

$$
L=10
$$

(b)

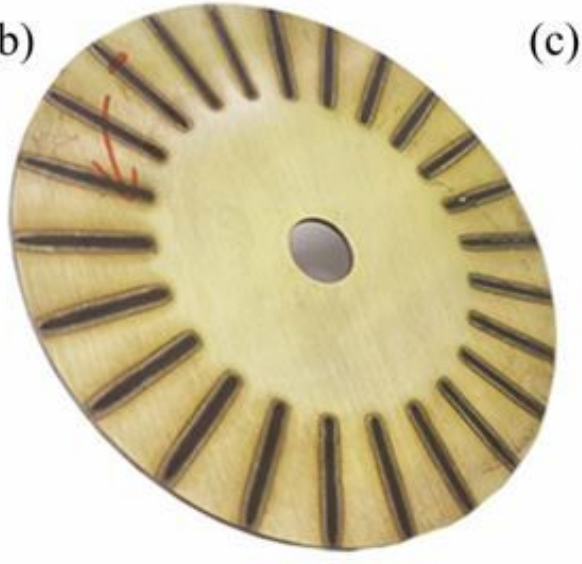

$L=20$

(c)

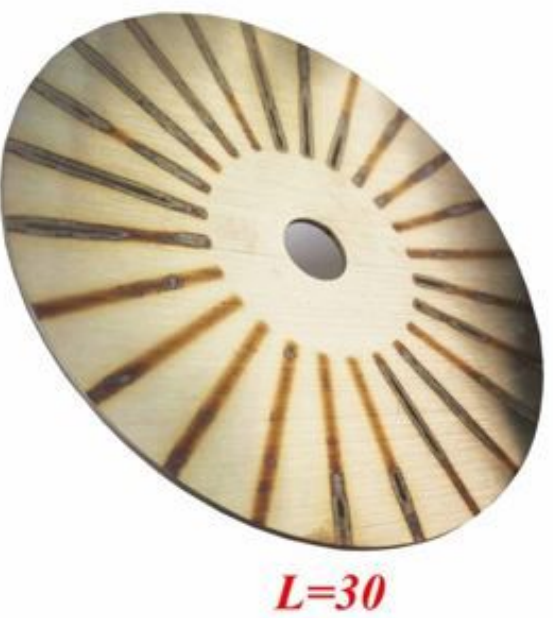

\section{Figure 13}

Experimental results of different heating line lengths. 


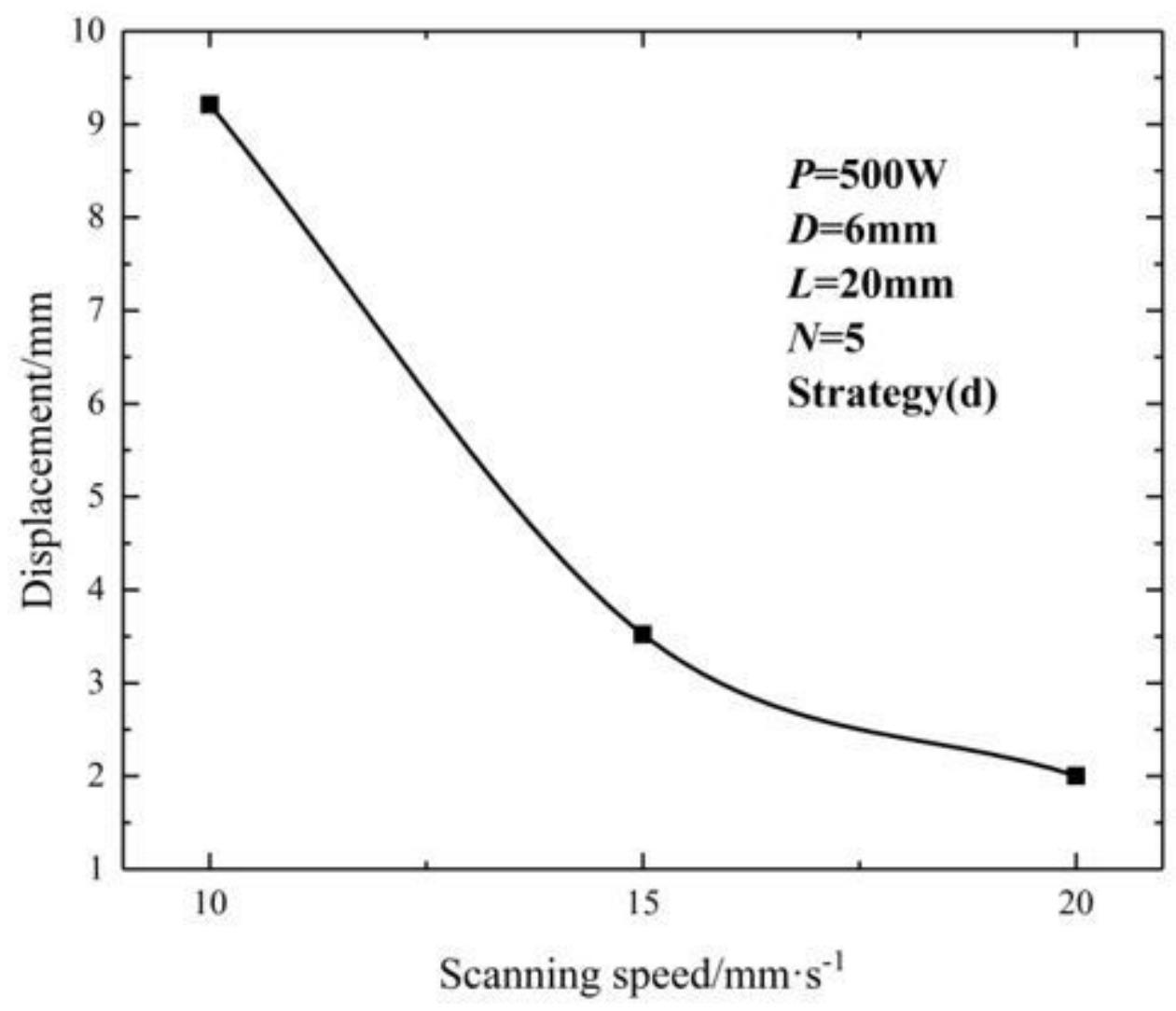

Figure 14

Influence of scanning speed on forming. 


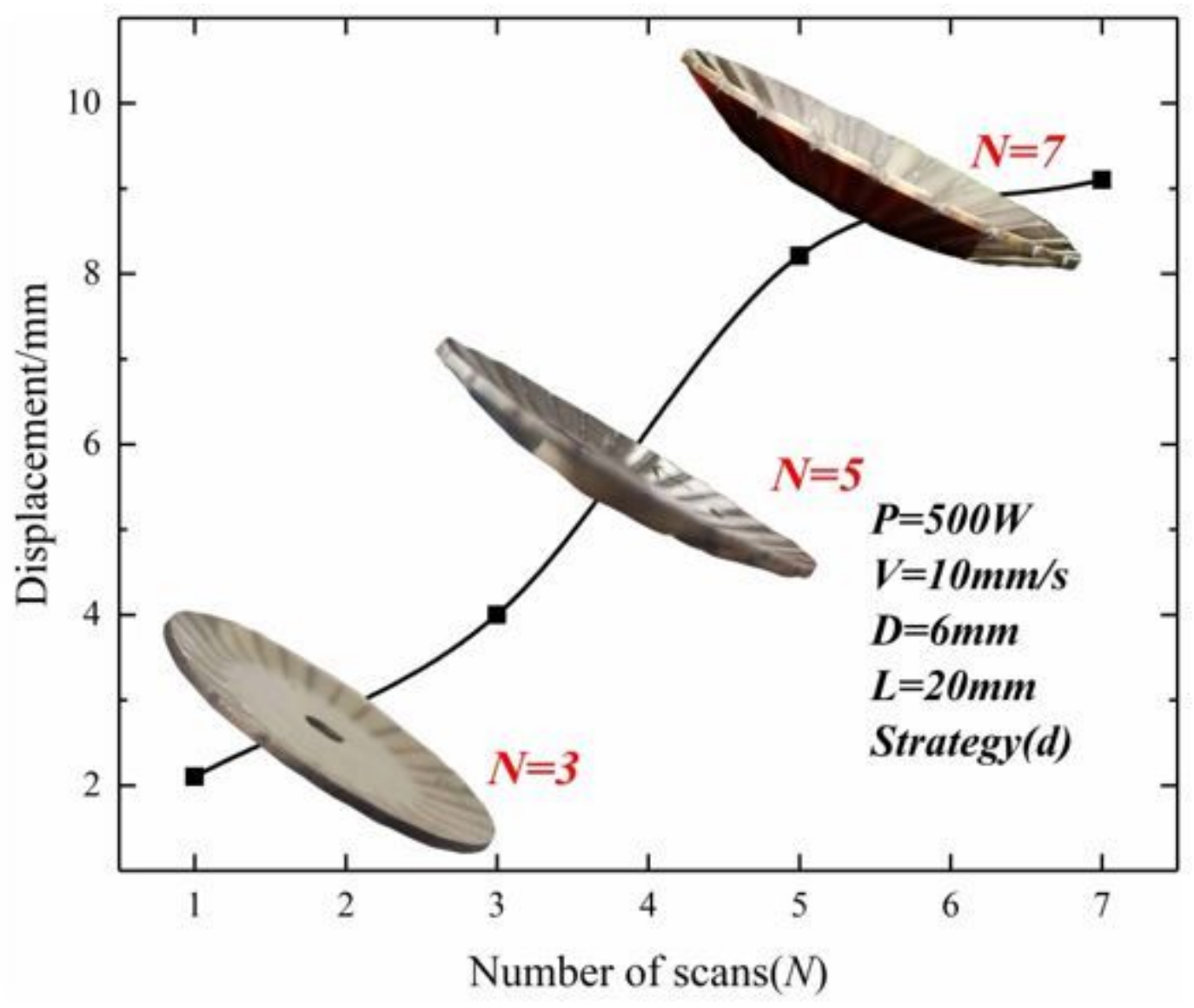

Figure 15

Influence of number of scans on forming. 